NBER WORKING PAPER SERIES

\title{
BIAS AGAINST NOVELTY IN SCIENCE: A CAUTIONARY TALE FOR USERS OF BIBLIOMETRIC INDICATORS
}

\author{
Jian Wang \\ Reinhilde Veugelers \\ Paula Stephan \\ Working Paper 22180 \\ http://www.nber.org/papers/w22180
NATIONAL BUREAU OF ECONOMIC RESEARCH
1050 Massachusetts Avenue
Cambridge, MA 02138
April 2016

Earlier versions of this paper were presented at the Workshop on the Organization, Economics and Policy of Scientific Research, Turin; Institute for Research Information and Quality Assurance, Berlin; Max Planck Institute for Innovation and Competition, Munich; and the TIES seminar at the MIT Sloan School, Cambridge. The authors thank seminar participants and in particular Pierre Azoulay, Christian Catalini, Paul David, Lee Fleming, Alfonso Gambardella, Dietmar Harhoff, Sybille Hinze, Stefan Hornbostel, Jacques Mairesse, Fabio Montobbio, Henry Sauermann, Daniel Sirtes, Scott Stern, Mark Veugelers, and John Walsh for helpful comments. Financial support from KU Leuven (GOA/12/003) and the Research Foundation - Flanders (FWO, G.0825.12) is gratefully acknowledged. J. Wang also gratefully acknowledges a postdoctoral fellowship from FWO. Publication data are sourced from Thomson Reuters Web of Science Core Collection. The views expressed herein are those of the authors and do not necessarily reflect the views of the National Bureau of Economic Research.

NBER working papers are circulated for discussion and comment purposes. They have not been peer-reviewed or been subject to the review by the NBER Board of Directors that accompanies official NBER publications.

(C) 2016 by Jian Wang, Reinhilde Veugelers, and Paula Stephan. All rights reserved. Short sections of text, not to exceed two paragraphs, may be quoted without explicit permission provided that full credit, including $(\odot$ notice, is given to the source. 
Bias against Novelty in Science: A Cautionary Tale for Users of Bibliometric Indicators Jian Wang, Reinhilde Veugelers, and Paula Stephan

NBER Working Paper No. 22180

April 2016

JEL No. I23,O31,O33,O38

\begin{abstract}
Research which explores unchartered waters has a high potential for major impact but also carries a higher uncertainty of having impact. Such explorative research is often described as taking a novel approach. This study examines the complex relationship between pursuing a novel approach and impact. Viewing scientific research as a combinatorial process, we measure novelty in science by examining whether a published paper makes first time ever combinations of referenced journals, taking into account the difficulty of making such combinations. We apply this newly developed measure of novelty to all Web of Science research articles published in 2001 across all scientific disciplines. We find that highly novel papers, defined to be those that make more (distant) new combinations, deliver high gains to science: they are more likely to be a top $1 \%$ highly cited paper in the long run, to inspire follow on highly cited research, and to be cited in a broader set of disciplines. At the same time, novel research is also more risky, reflected by a higher variance in its citation performance. In addition, we find that novel research is significantly more highly cited in "foreign" fields but not in its "home" field. We also find strong evidence of delayed recognition of novel papers and that novel papers are less likely to be top cited when using a short time window. Finally, novel papers typically are published in journals with a lower than expected Impact Factor. These findings suggest that science policy, in particular funding decisions which rely on traditional bibliometric indicators based on short-term direct citation counts and Journal Impact Factors, may be biased against "high risk/high gain" novel research. The findings also caution against a mono-disciplinary approach in peer review to assess the true value of novel research.
\end{abstract}

Jian Wang

KU Leuven

MSI \& ECOOM

Naamsestraat 69

3000 Leuven, BELGIUM

jian.wang@kuleuven.be

Reinhilde Veugelers

KU Leuven

MSI \& ECOOM

Naamsestraat 69

3000 Leuven

BELGIUM

and Bruegel and CEPR

reinhilde.veugelers@econ.kuleuven.be
Paula Stephan

Department of Economics

Andrew Young School of Policy Studies

Georgia State University

Box 3992

Atlanta, GA 30302-3992

and NBER

pstephan@gsu.edu 


\section{Introduction}

Scientific breakthroughs advance the knowledge frontier. Research underpinning breakthroughs often is driven by novel approaches. While research that takes a novel approach has a higher potential for major impact, it also faces a higher level of uncertainty of impact. In addition, it may take longer for novel research to have a major impact, either because of resistance from incumbent scientific paradigms (Kuhn, 1962; Merton, 1973; Planck, 1950) or because of the longer time required to incorporate the findings of novel research into follow-on research (Garfield, 1980; Wyatt, 1975). The "high risk/high gain” nature of novel research makes it particularly appropriate for public support (Arrow, 1962). Delayed recognition may, however, lead novel research to be undervalued in research evaluations which use classic bibliometric indicators based on short term citations.

This bias in classic bibliometric indicators against novel research, to the extent it exists, is of concern given the increased reliance funding agencies and hiring institutions place on bibliometric indicators to aid in decision making and performance evaluation (Butler, 2003; Hicks, 2012; Hicks, Wouters, Waltman, de Rijcke, \& Rafols, 2015; Martin, 2016; Monastersky, 2005). Such heavy reliance may explain in part the perception that funding agencies and their expert panels are increasingly risk-averse and the charge that competitive selection procedures encourage relatively safe projects, which exploit existing knowledge, at the expense of novel projects, that explore untested approaches (Alberts, 2010; Azoulay, Graff Zivin, \& Manso, 2011; Kolata, 2009; NPR, 2013; Petsko, 2012; Walsh, 2013).

The goal of this paper is to develop a measure of novel research and compare the citation profile of novel research with that of non-novel research as well as the Impact Factor of the journals in which novel research is published. We are particularly interested in whether characteristics of novel research match the "high risk/high gain" profile associated with breakthrough research and whether bibliometric measures are biased against novel research. To this end, we define research that draws on new combinations of knowledge components as novel and develop an ex ante measure of combinatorial novelty at the paper level, where novelty is operationalized as making new combinations in referenced journals. Utilizing this newly-minted measure of novelty, we explore the complex relationship between novelty and citation impact, using the life-time citation 
trajectories of 773,311 research articles across all scientific disciplines published in 2001 and indexed in the Web of Science (WoS), as well as the profile of papers citing them.

We find novel papers to have a larger variance in their citation distribution and be more likely to populate both the tail of high impact as well as the tail of low impact, reflecting their "high risk" profile. At the same time, novel papers also display a "high gain" characteristic: They have a much higher chance of being a top cited paper in the long run, a higher likelihood of stimulating follow-on top cited research, and a broader impact transcending disciplinary boundaries and reaching more scientific fields. We further scrutinize the impact profile of novel research and uncover intriguing characteristics associated with novelty. First, we distinguish between impact in "home" and "foreign" fields and find that novel papers are significantly more likely to be highly cited in foreign fields but not in their home field. Second, an examination of time dynamics in the citation accumulation process reveals delayed recognition for novel research. Specifically, although novel papers are highly cited in the long run, they are less likely to be top cited in the short run. We also find that novel papers are less likely to be published in high Impact Factor journals. These findings suggest that over-reliance on standard bibliometric metrics, in particular Journal Impact Factor and short-term citation counts, may bias against novel research.

\section{Combinatorial novelty in science}

We view the process of research as one of puzzle solving, whereby researchers work with pieces of knowledge and combine them to generate new scientific knowledge. Some of these existing knowledge pieces are embedded in the literature, some in equipment and materials, which themselves are embedded in the literature, and others in the tacit knowledge of individuals engaged in the research. Using knowledge pieces in well-understood ways corresponds to a search process labeled as exploitation. Using existing knowledge pieces in new ways corresponds to an explorative search process, which is more likely to lead to major breakthroughs but also comes with a substantial risk of no or low impact (March, 1991). From this perspective, novel research is more closely associated with exploration.

Drawing on this combinatorial perspective of the research process, novelty can be defined as the recombination of pre-existing knowledge components in an unprecedented fashion. This 
combinatorial view of novelty has been embraced by scholars in various disciplines (Arthur, 2009; Burt, 2004; Mednick, 1962; Schumpeter, 1939; Simonton, 2004; Weitzman, 1998). For example, Nelson and Winter (1982) state that "the creation of any sort of novelty in art, science or practical life - consists to a substantial extent of a recombination of conceptual and physical materials that were previously in existence.” Romer (1994) and Varian (2009) also argue that new combinations of existing components provide a potentially huge source of important new discoveries. The ability to make new combinations of existing knowledge pieces is one reason that "outsiders" from other disciplines arguably can provide exceptional insights when they move from one field to another, as physicist Leo Szilard did, when he switched from physics to biology in the 1950s (Carroll, 2013, p. 352).

It is important to note that not all breakthroughs result from combinatorial novelty, and certainly not all novel research leads to breakthroughs. It is also important to note that there is strong anecdotal evidence that research of a novel nature not only has the potential to become a breakthrough but also contributes to subsequent breakthroughs. The diagrams that Feynman produced in the late 1940s provided physicists with an entirely new way of understanding the behavior of subatomic particles and, according to the historian of physics David Kaiser, "have revolutionized nearly every aspect of theoretical physics” (Kaiser, 2009, p. 4). The creation of transgenic and knockout mice in the late 1980s revolutionized research on any number of diseases. Or, consider the research of Sebastian Seung that has received considerable attention and aims at mapping the human brain, something that no one to date has done (Cook, 2015). Seung's course is heavily influenced by applying a method described in a highly-cited paper published in PloS BIOLOGY (Denk \& Horstmann, 2004) that used a novel approach in human connectome (cf infra).

The combinatorial view of novelty has been studied in the technological invention literature and operationalized using patent information. Fleming (2001) takes the technology subclasses in which patents are classified as representing the components of technological know-how. Fleming (2007) looks at the occurrence of new combinations of subclasses to which a patent is assigned and uses this as a measure of the generative creativity of inventors of the patent. Verhoeven, Bakker, and Veugelers (2016) combine this combinatorial novelty measure with a measure of novelty in technological and scientific knowledge origins, based on whether the focal 
patent cites other technological inventions or scientific literature from areas that were never cited before in its patent class. They find that the combination of the combinatorial novelty and the novelty in knowledge origins is a powerful identifier of breakthrough inventions.

Uzzi, Mukherjee, Stringer, and Jones (2013) apply a conceptually similar approach to scientific publications. They propose to trace the combinatorial process underlying the research from the references of the published paper. Operationally, they view journals as bodies of knowledge pieces and calculate the relative commonness for each pair of journals referenced by a paper. For this individual paper, they then use the lowest $10^{\text {th }}$ percentile commonness score of its series of commonness scores as an indication of its "novelty" and the median commonness score as an indication of its "conventionality." They find that papers with both high novelty and conventionality are more likely to become top cited. Lee, Walsh, and Wang (2015) adapt the Uzzi et al. (2013) measure for their study of creativity in scientific teams and find that team characteristics, i.e., size, and field and task variety, have different effects on novelty than on impact of the publication produced by the team.

Other approaches to assess combinatorial novelty in science also exist in the literature. Boudreau, Guinan, Lakhani, and Riedl (forthcoming), for example, identify whether a proposal to the NIH departs from the existing literature, by examining all possible pairs of MeSH (Medical Subject Headings) terms in the proposal and then calculating the fraction of the pairs which have not appeared in all the previous literature in PubMed. They find that evaluators systematically give lower scores to highly novel research proposals. Azoulay, Güler, Koçak, Murciano-Goroff, and Anttila-Hughes (2012) measure the recombinative character of a publication in a similar manner, examining the extent to which pairs of its MeSH descriptors are unusual. Using this measure, they find a positive relationship between the recombinative nature of a paper and the breadth of its citations but a negative relationship between the measure and citation volume.

Following the combinatorial novelty approach, we assess the novelty of a research article by examining the extent to which it makes novel combinations in prior knowledge components. In operationalizing the combinatorial novelty approach, we follow Uzzi et al. (2013) and use journals as bodies of knowledge components. Rather than looking at the atypicality of 
referenced journal pairs as do Uzzi et al. (2013), we focus specifically on the novelty of referenced journal pairs by examining whether a pair has never been made in prior publications and is thus new. Furthermore, we take into account the knowledge distance between the newlycombined journals based on their co-cited journal profiles, i.e., their common "friends", to assess the difficulty of making the new combination. More precisely, we measure the novelty of a paper as the number of new journal pairs in its references weighted by the cosine similarity between the newly-paired journals.

\section{Measuring novelty of scientific publications}

\subsection{Procedure}

We construct our novelty indicator for research articles published in 2001 and indexed in the Thomson Reuters Web of Science Core Collection (WoS), based on their references.

- For each paper, we retrieve all of its referenced journals and pair them up (i.e., $J_{1}-J_{2}, J_{1}-J_{3}$, $\left.J_{1}-J_{4} \ldots\right)$.

- We examine each journal pair to see whether it is new, i.e., has never appeared in prior literature starting from $1980^{1}$.

- For those new journal pairs (e.g., $J_{1}-J_{2}$ ), we assess how easy it is to make this new combination, by investigating how many common "friends" the paired journals have. More precisely, we compare the co-citation profiles of the two journals ( $J_{1}$ and $J_{2}$ ) in the preceding three years (between year $t-3$ and $t-1$ ).

o We use the following matrix where each row or column provides the co-citation profile for a journal. The $i, j$-th element in this symmetric matrix is the number of times that $J_{i}$ and $J_{j}$ are co-cited, that is, the number of papers published between year $t-3$ and $t-1$ that cite the two journals together. For example, in the preceding three years, the pair $J_{1}$ and $J_{2}$ have never been cited together by any papers (as this pair is new), but $J_{1}$ and $J_{3}$ have been cited together by 3 papers, and $J_{2}$ and $J_{3}$

\footnotetext{
${ }^{1}$ The 1980 cut off is because of data-availability reasons. It assumes a window of 20 years before obsolescence.
} 
have been cited together by 6 papers, making $J_{3}$ a common friend of $J_{1}$ and $J_{2}$, as is journal $J_{5}$.

\begin{tabular}{|l|l|l|l|l|l|l|}
\hline & $\mathrm{J}_{1}$ & $\mathrm{~J}_{2}$ & $\mathrm{~J}_{3}$ & $\mathrm{~J}_{4}$ & $\mathrm{~J}_{5}$ & $\ldots$ \\
\hline $\mathrm{J}_{1}$ & $/$ & 0 & 3 & 0 & 5 & $\ldots$ \\
\hline $\mathrm{J}_{2}$ & 0 & $/$ & 6 & 2 & 3 & $\ldots$ \\
\hline $\mathrm{J}_{3}$ & 3 & 6 & $/$ & 5 & 4 & $\ldots$ \\
\hline $\mathrm{J}_{4}$ & 0 & 2 & 5 & $/$ & 0 & $\ldots$ \\
\hline $\mathrm{J}_{5}$ & 5 & 3 & 4 & 0 & $/$ & $\ldots$ \\
\hline$\ldots$ & $\ldots$ & $\ldots$ & $\ldots$ & $\ldots$ & $\ldots$ & $/$ \\
\hline
\end{tabular}

o The ease of combining $J_{1}$ and $J_{2}$ is then defined as the cosine similarity between their co-citation profiles:

$$
\operatorname{CoS}_{1,2}=\frac{J_{1} \cdot J_{2}}{\left\|J_{1}\right\|\left\|J_{2}\right\|}
$$

where $J_{1}$ and $J_{2}$ are row (or column) vectors. Cosine similarity is a classic measure of similarity between two vectors and is widely used in bibliometrics.

o Correspondingly, the difficulty score of combining $J_{1}$ and $J_{2}$ is: $1-\operatorname{CoS}_{1,2}$.

- For each paper, we construct a continuous measure of combinatorial novelty as the sum of the difficulty scores of making the new combinations. Papers without new combinations get 0 by definition.

$$
\text { Novelty }=\sum_{J_{i^{-} J_{j}} \text { pair is new }}\left(1-\operatorname{COS}_{i, j}\right)
$$

- We also construct two alternative measures for robustness tests (details in Appendix III): the maximum novelty score which focuses exclusively on the novelty score of the most distant new journal pair and the weighted share of new journal pairs in all pairs, which is essentially a means of normalizing our novelty measure for the number of all journal pairs.

- In addition, to avoid trivial combinations, we focus only on the most important journal combinations, i.e., we exclude 50 percent of the least cited journals (as measured in the preceding three years). To further reduce the likelihood of picking up trivial combinations, we impose as a condition that the new combination must be reused at least 
once in the next three years. We check the robustness of the main results to these choices in Appendix III.

\subsection{Illustration}

We use the paper coauthored by Denk and Horstmann (2004), "Serial Block-Face Scanning Electron Microscopy to Reconstruct Three-Dimensional Tissue Nanostructure” published in PLOS Biology to illustrate and validate our novelty measure.

Denk’s team developed a method called Serial Block-Face Scanning Electron Microscopy (SBFSEM), which combines slicing and imaging by placing an ultra-microtome inside the chamber of a scanning electron microscope. The microscope scans the surface of the tissue block, and then the microtome shaves a thin slice off and exposes the next layer for a subsequent round of imaging. The researchers made a new and effective combination between an environmental scanning electron microscope and a special-designed ultra-microtome. While both components already existed and were in use, the combination is new. This new combination not only provides an automated method to collect serial images with sufficient resolution to trace even the thinnest axons and to identify connections between individual neurons but also overcomes many other problems. For example, it produces uninterrupted series of aligned images without section loss, contamination, or distortion, which often arise from manual sectioning and imaging. This work has opened the possibility of automatically generating serial images for reconstructing the neural network. It has also revitalized the dream of mapping the human brain and is contributing to the research of a number of scientists, including that of Sebastian Seung, mentioned supra.

The PLOS Biology paper cites 19 WoS-indexed journals. Of all possible journal pairs (171), 9 journal pairs are new, using the procedure described supra. Each of these new journal pairs involves an article from Nature Materials (subject categories: Chemistry, Physical; Materials Science, Multidisciplinary; Physics, Applied; and Physics, Condensed Matter), which is combined with articles from journals in subject categories of Neurosciences; Cell Biology; and Physiology. The cosine similarity for each of the 9 combinations is extremely low, indicating that each of the new combinations have few common friends and are therefore relatively difficult 
to make. This leads to an overall score on novelty of 8.9891 for the Denk and Horstmann paper, which places the paper in the top $1 \%$ of novel papers in its field.

PLOS Biology (where the paper was published) had an Impact Factor of 13.868 in 2004, which ranked it in the upper quartile (Q1) in both of its subject categories: Biology and Biochemistry \& Molecular Biology. The paper was not among the top 1\% highly cited papers in the subject category of Biology until 2012 and in the subject category of Biochemistry \& Molecular Biology until 2013. Papers citing it include several articles published in Nature and Science, some of which are top cited papers. Appendix I describes the calculation of the novelty score for the Denk and Horstmann paper in more details.

The Denk and Horstmann paper thus illustrates how research that is combinatorially novel has reference pairs that are new.

\section{Data and descriptive statistics}

To explore the properties of novelty and its relationship with impact, we use a dataset consisting of all research articles ${ }^{2}$ in WoS published in 2001 from all the 251 subject categories. There are 773,311 articles in total, and 674,546 of them have at least two references to WoS journals. Among these 674,546 articles, 203 have no subject category information and therefore are also excluded, and 274,072 articles have more than one subject category (up to six subject categories) and are counted multiple times. The final 2001 dataset used has 1,056,936 observations.

We expect our measure to identify only a small minority of papers as novel, since the majority of research is of an exploitative rather than an exploratory nature. Indeed we find that relatively few papers make new referenced journal combinations. To be more specific, $89 \%$ of all papers in our sample make no new combinations of referenced journal and therefore do not score on the novelty measure. Of the $11 \%$ that make new journal combinations, most (55\%) make only one new combination, and only 7\% have more than 5 new combinations. Most of the novel papers score only modestly on our distance-weighted novelty indicator. At the other end of the distance

\footnotetext{
${ }^{2}$ Since we are interested in original research, we keep only publications labeled as "article” in WoS but exclude other document types such as "review" and "letter."
} 
distribution, we find the top 10 percentile to have a score on our distance weighted indicator in the range of the interval (5-248).

Insert Table 1 here

Overall, our measure of novelty displays a highly skewed phenomenon of novelty in scientific publications. We are particularly interested in papers which are highly novel. Therefore, we construct a categorical novelty variable NOV CAT: (1) non-novel, if a paper has no new journal combinations, (2) moderately novel, if a paper makes at least one new combination but has a novelty score lower than the top 1\% of its subject category, and (3) highly novel, if a paper has a novelty score among the top $1 \%$ of its subject category.

Highly novel papers not only make more but also more distant new combinations. The median number of new combinations they make is 7 , while the median for moderately novel papers is 1 . In addition, the new combinations that highly novel papers make are more distant, as suggested by their lower cosine similarity scores compared with that of moderately novel papers (Table 1).

In addition, fields differ in their propensity to make new combinations. The Life Sciences score relatively higher, especially Neurosciences, Pharmacology and Biology \& Biochemistry. The Physical Sciences score relatively low on novelty, especially Space Sciences and Physics. Social Sciences, especially Psychology, score above most fields ${ }^{3}$. Field difference in the novelty intensity may be partly explained by their heterogeneous patterns of publishing and referencing. In the econometric analysis we control for scientific field (i.e., WoS subject category) specific effects.

\section{Novelty and impact}

\subsection{High risk of novel research}

In view of the risky nature of novel research, we expect novel papers to have a higher variance in their citation performance. Following Fleming (2001), the Generalized Negative Binomial

\footnotetext{
${ }^{3}$ By construction, there is no field differences in the relative share of highly novel (i.e., NOV CAT = 3) papers: NOV CAT3 is defined as the top 1\% novel papers within given subject categories.
} 
(GNB) model is adopted to estimate the effects of novelty on the distribution characteristics of received citations. Specifically, GNB assumes that the number of citations (i.e., the dependent variable) follows a negative binomial distribution and allows us to model the natural logarithm of the mean $\mu$ and the natural logarithm of the dispersion parameter $\alpha$ each by a linear equation of novelty and other control variables. The variance of the distribution is $\sigma^{2}=\mu+\alpha \mu^{2}$. For fitting the model the STATA function gnbreg is implemented (StataCorp, 2016).

We use a 14-year time window to count citations for our set of 2001 papers, which is deemed sufficiently long across fields (Wang, 2013). We control for other confounding factors with potential influence on the relationship between novelty and impact. First, we control for specific scientific field effects (cf supra), by including the complete set of dummies for the 251 WoS subject categories. Second, we control for the number of references made in the focal paper, which might increase both the likelihood of having new combinations and the number of received citations (Bornmann, Leydesdorff, \& Wang, 2014; Lee et al., 2015) ${ }^{4}$. Third, we take into account the size and nature of the collaborative effort, which might affect both novelty and impact (Adams, Black, Clemmons, \& Stephan, 2005; Katz \& Hicks, 1997; Lee et al., 2015; Wang, Thijs, \& Glänzel, 2015). Specifically, we include the number of authors and whether the paper is internationally coauthored as additional controls.

GNB model estimates are reported in Table 2 and illustrated in Figure 1A. Compared with nonnovel papers, ceteris paribus, moderately novel papers receive on average $2.78 \%$ more citations, and highly novel papers receive $12.04 \%$ more citations. At the same time, the higher average impact of novel papers is accompanied by a higher dispersion in citation performance. This holds however for only the highly novel papers. The dispersion of the citation distribution is 14.90\% higher for highly novel papers than non-novel papers.

Insert Table 2 here

Insert Figure 1 here

\footnotetext{
${ }^{4}$ Controlling for the number of references is particularly important, as our measure of novelty is not expressed as a share of all references.
} 
A higher dispersion in impact can be driven by more extreme successes and/or more cases of uncited or rarely cited papers. Therefore, we examine in which tail of high and low impact the highly novel papers are more likely to be. We do this using multinomial logistic regression (Table 3). We classify papers, within the same WoS subject category and publication year, into three citation classes based on their citations in the 14-year time window: the top $10 \%$, the lowest $10 \%$, and the middle $80 \%$. There is clear evidence that highly novel papers, which have a higher dispersion in their citations, are more likely to be in the tail of high impact, specifically, the odds of being the top $10 \%$ cited versus being the middle $80 \%$ cited are $16.80 \%$ higher for highly novel than non-novel papers. There is equally strong evidence that highly novel papers are more likely to be in the tail of least cited papers: the odds of being in the lowest $10 \%$ cited versus being in the middle $80 \%$ cited are $16.76 \%$ higher for highly novel than non-novel papers. In other words, the higher dispersion in citations for highly novel papers is driven by both tails of high and low impact and therefore reflects their higher level of uncertainty. On the other hand, moderately novel papers are only more likely to be in the top tail but not in the lower tail, displaying a lower level of uncertainty compared with highly novel papers, in line with the GNB results.

\section{Insert Table 3 here}

\subsection{High gain from novel research}

While novel research faces a higher level of risk, we also expect, as argued supra, novel research to have a higher probability of making a significant contribution to research. We first examine whether novel papers are more likely to become "big hits," i.e., receive an exceptionally large number of citations, defined here, following the bibliometric convention, as being top $1 \%$ highly cited in the same WoS subject category and publication year. Logistic regression controlling for previously mentioned other potential confounding factors reveals that the odds of a big hit are 39.82\% higher for highly novel papers and $11.22 \%$ higher for moderately novel papers, compared with comparable non-novel papers (Table 4 column 1 and Figure 1B).

Insert Table 4 here 
Second, we find that novel papers are more likely to be cited by other big hits. Novel research is therefore not only more likely to become a big hit itself but also more likely to stimulate followon research which generates major impact. Specifically, we find that papers that cite novel papers are more likely to themselves receive more citations, compared with papers citing nonnovel papers (Appendix II Table A3). Likewise, the probability of being cited by an article which itself becomes a big hit is also higher for highly novel papers than for non-novel papers. We use a logistic model to estimate the probability of a paper being cited by big hits, teasing out any contamination from direct citations received, in addition to controlling for previously mentioned other confounding factors. We observe that the odds of being cited by big hits are $26.20 \%$ higher for a highly novel paper than for comparable non-novel papers receiving the same number of citations (Table 4 column 2 and Figure $1 C)^{5}$. Compared with highly novel papers, moderately novel papers demonstrate a much smaller advantage over non-novel papers. The odds of being cited by big hits are 3.56\% higher for a moderately novel paper than a comparable non-novel paper.

\subsection{Transdisciplinary impact of novel research}

We explore the breadth of impact, that is, whether novel research is cited across more scientific fields than is non-novel research. We use the number of subject categories citing the focal paper in the14 years after publication as the dependent variable and estimate a Poisson model. The Poisson model additionally controls for the number of citations, given that papers with more citations are more likely to be cited by more fields. Results show that, compared with non-novel papers receiving the same number of citations and having the same values on all other control variables, highly and moderately novel papers are cited by $16.56 \%$ and $10.05 \%$ more subject categories, respectively (Table 4 column 3 and Figure 1D).

\footnotetext{
${ }^{5}$ In this analysis, big hits, which cite the focal paper, are identified as the top $1 \%$ highly cited papers in the same subject category and publication year, based on their cumulative citations till the end of 2014. Given that we do not have a sufficiently long time window to count citations for very recent papers, we only account for big hits between 2001 and 2009 and accordingly test whether novel papers are more likely to be cited by big hits in the 9-year period from 2001 to 2009. Correspondingly, we control for the number of direct citations in the same 9-year period.
} 
We examine whether the impact of a novel paper is more likely to be outside its own field than within its own field. To this end, we partition a paper's forward citations into two types: "home" and "foreign" field citations, that is, citations received from subsequent publications that share at least one common WoS subject category (home field citations) and citations from publication that share no common WoS subject categories (foreign field citations). Then we calculate, for each paper, the proportion of its citations that are foreign field citations. An OLS model (Table 4 column 4) shows that novel papers have a larger ratio of citations from foreign fields, suggesting that novel research has a greater transdisciplinary impact than does non-novel research ${ }^{6}$.

The broader and more transdisciplinary impact of novel research raises the question of whether the major impact that novel papers generates is driven by their impact within and/or outside their own field. To answer this question we examine separately whether novel papers are among the top 1\% highly cited in their home field and in foreign fields (Table 4 columns 5-6 and Figure $1 E)^{7}$. We find that the odds of being top cited in home fields are not significantly larger for highly novel papers than non-novel papers, and for moderately novel papers they are even 8.37\% lower compared with that of non-novel papers. The lower chance for novel papers to be highly cited in their home field is consistent with resistance from existing paradigms against novel approaches. At the same time, novel papers, compared with non-novel ones, have higher odds of being highly cited in foreign fields. Although this holds for moderately novel papers, it especially holds for highly novel papers, i.e., the odds of being highly cited in foreign fields are 29.39\% and 62.37\% higher for moderately and highly novel papers respectively, compared with that of non-novel papers. The finding that the overall high impact of novel research is due to its success in foreign fields rather than in its home field calls to mind the passage from Luke 4:24: "Verily I say unto you, No prophet is accepted in his own country."

\footnotetext{
${ }^{6}$ The findings that novel papers has an impact which is broader and more transdisciplinary (i.e., are cited by more fields and have a larger ratio of foreign field citations) are robust when we additionally control for the number of WoS subject categories that the focal paper itself is affiliated with (Appendix II Table A4).

${ }^{7}$ It is important to note that a paper being highly cited in foreign fields means that, compared with other papers in the same WoS subject category and publication year, its number of citations from foreign fields is among the top $1 \%$ highest. It does not mean that this paper is among the top $1 \%$ highly cited in a specific foreign field compared with all other papers based on their citations in this specific field.
} 


\subsection{Delayed recognition for novel research}

The major impact of novel research may take longer to realize, for instance, because of resistance from existing paradigms. To explore the extent to which delays in recognition occur, we estimate the probabilities of being a top 1\% highly cited paper for non-, moderately-, and highly- novel papers for citation windows ranging from 1 to 14 years. We find that highly novel papers are less likely to be top cited when using citation time windows shorter than 3 years (Table 5, Figure 1F, and Figure 2A). As of the fourth year after publication, highly novel papers are significantly more likely to be top cited, and their advantage over non-novel papers increases with the length of the time window. Moderately novel papers suffer even more from delayed recognition. They are less likely to be top cited when using citation windows shorter than 5 years, and they only have a significantly higher chance of being a big hit with windows of at least 9 years.

Insert Table 5 here

Insert Figure 2 Here

The well-known fact that it takes longer for papers in one field to be cited in another field (Rinia, Van Leeuwen, Bruins, Van Vuren, \& Van Raan, 2002) raises the question of whether the finding of delayed recognition for novel research is driven by their large share of citations that come from foreign fields. We unravel the delayed recognition results further by comparing the time profile in recognition separately for home and foreign fields. A number of interesting results emerge.

First, the lower impact which novel papers face in their home field compared with non-novel papers shrinks over time, showing that delayed recognition for novel papers exists in their home field (Appendix II Table A5 and Figure 2B). More specifically, we find that highly novel papers, compared with non-novel papers, are significantly less likely to be top cited in their home field in the first five years, but this disadvantage disappears when using a longer window. Moderately novel papers, however, are consistently, over time, significantly less likely to be top cited in their home field compared with non-novel papers. Nevertheless, the gap with non-novel papers in the 
probability of being top cited in the home field shrinks over time for moderately novel papers, just as it does for highly-novel papers.

Second, the higher impact of novel papers in foreign fields compared with non-novel papers magnifies over time, suggesting the delayed recognition for novel papers also exists in foreign fields (Appendix II Table A6 and Figure 2C). We find that both moderately and highly novel papers are more likely to be highly cited in foreign fields than non-novel papers, but this advantage requires a citation time window of at least three and four years for highly and moderately novel papers, respectively. Moreover, the foreign advantage of novel papers clearly increases over time.

Third, as Appendix II Figure A1 shows, impact in foreign fields takes longer to materialize than that in home fields. For all papers, regardless of novelty, the average number of annual citations in foreign fields, compared with that of home fields, is smaller in the first seven years but greater in later years. This implies that it takes time for larger success of novel papers in foreign fields to compensate for their lack of advantage in their home fields. This is illustrated by Appendix II Figure A2 which shows that it takes time for the advantage that novel papers enjoy in foreign fields to cancel out any disadvantage they have in home fields. In sum, the overall delayed recognition for novel papers is a composite effect consisting of a delayed recognition both in home as well as in foreign fields and a delayed process in knowledge diffusion to other fields.

\subsection{Bias against novelty}

The finding of delayed recognition for novel research bears direct implications on the use of bibliometric indicators in science policy. As novel papers suffer from delayed recognition and need a sufficiently long citation time window before reaching the status of big hit, standard bibliometric indicators which use short citation time-windows (typically two or three years) are biased against novelty.

In this section, we explore further how novel research performs on standard bibliometric indicators, beyond the bias generated by short citation windows. Specifically, we examine the Journal Impact Factor, probably the most commonly used and influential bibliometric indicator

for assessing the quality of journals and their articles. We investigate whether novel papers, with 
their "high risk/high gain" nature, are more or less likely to be published in high Impact Factor journals. We find that although novel papers are published on average in journals with higher Impact Factors, compared with non-novel ones (Appendix II Table A2), the Poisson regression, controlling for other confounding factors such as field differences, reveals that the Journal Impact Factor of moderately- and highly-novel papers is significantly and substantially lower (approximately $10.55 \%$ and $18.11 \%$ respectively) than comparable non-novel papers (Table 6 and Figure 3). This finding - that novel papers are published in journals with Impact Factors below their potential - suggests that novel papers encounter obstacles in being accepted by journals holding central positions in science. Moreover, the negative association between novelty and Journal Impact Factor is not due to novel papers being more likely to be published in new journals. Regression analyses which additionally control for journal age or whether the journal is new confirms that novel papers are published in lower Impact Factor journals than expected (Table 5). The increased pressure journals are under to boost their Impact Factor (Martin, 2016) and the fact that the Journal Impact Factor is based on citations in the first two years after publication ${ }^{8}$ suggests that journals may strategically choose to not publish novel papers which are less likely to be highly cited in the short run.

Insert Table 6 here

Insert Figure 3 here

Another question is whether the negative association between novelty and Journal Impact Factor is responsible for the delayed recognition faced by novel research. To address this question, we examine whether the novelty effect on the probability of big hits is contingent on the Journal Impact Factor. If publication in a low Impact Factor journal is responsible for the delayed recognition encountered by novel papers, we expect that novel papers which succeed in getting in high Impact Factor journals would not suffer from delayed recognition. Therefore, we reestimate the models in Table 5, additionally controlling for the Journal Impact Factor and incorporating interaction effects between novelty and whether the journal in which the focal paper is published has a top $10 \%$ Impact Factor in its subject category. As shown in Appendix II

\footnotetext{
${ }^{8}$ Journal Impact factor is essentially the average number of citations received in the current year by papers published in the preceding two years. http://wokinfo.com/essays/impact-factor/
} 
Table A7 and Figure 4, novel papers published in high Impact Factor journals still have a delayed citation accumulation process compared with non-novel papers in high Impact Factor journals. We conclude that delayed recognition is not entirely due to publication of novel works in journals with lower than expected Impact Factors.

\section{Insert Figure 4 here}

\subsection{Novelty and quality}

Our research demonstrates that standard bibliometric indicators, especially short-term citation windows and the Journal Impact Factor, are biased against novel papers. One might argue that such "bias" simply reflects the low quality associated with novel research. This raises the potential issue concerning unobserved and uncontrolled heterogeneity in paper quality. If novel research is associated with low quality, this would indeed explain the observation that novel papers are less likely to be highly cited in the short run and are less likely to be published in high Impact Factor journals, but it cannot explain why novel papers are more likely to eventually become highly cited and be cited in broader fields. On the other hand, if novel research is associated with high quality, then it would explain its long-term big impact but not its delayed recognition, or its lower Journal Impact Factor, or the fact that novel papers which are published in high Impact Factor journals still display a delayed recognition. Although we cannot completely rule out the possible link between novelty and quality, due to the lack of a proper measure for the true ex ante quality of a paper, the citation patterns of novel research that we find in this paper suggest something different than a clear association between novelty and quality. Therefore, we can at least conclude that novelty affects ex post impact in a non-trivial fashion which is difficult to explain by ex ante quality.

\subsection{Robustness analysis}

We ran a set of robustness tests on our findings. Details are reported in Appendix III. First, we tested whether our findings are robust across scientific fields. All our findings are robust for hard sciences and engineering, but several findings are not robust for social sciences and humilities. Although this may suggest that our findings hold only for hard sciences, it is more likely due to the insufficient coverage of WoS for humanities and social sciences (Hicks, 2004). 
Second, we examined whether our findings are sensitive to variations of our novelty measure. Our novelty measure is essentially a distance-weighted number of new combinations, and we tested two alterative formulations, i.e., the maximum novelty score which focuses exclusively on the novelty score of the most distant new journal pair and the weighted share of new journal pairs in all pairs, which is essentially a means of normalizing our novelty measure for the number of all journal pairs. Results are consistent when using these alterative formulas.

Our novelty measure excluded $50 \%$ of the least cited journals and required that the new combination of journals is reused in the next three years. Relaxing these constrains yielded robust results. Our results are also robust to additional constraints, such as excluding top 10\% highly cited journals and multidisciplinary journals.

We used categorical novelty measures in our regression analysis (i.e., highly-, moderately-, and non-novel). We duplicated the results using the natural logarithm transformed continuous novelty score in the regression and obtained robust results. We classified papers with the highest $1 \%$ novelty score as highly novel. Using alterative thresholds, i.e., top $0.1 \%$ and $5 \%$, also yielded consistent results.

Third, all our findings remain consistent and significant when we additionally control for the Uzzi et al. (2013) measure of atypicality in the regressions. More importantly, compared with Uzzi et al. (2013) measure of atypicality, our novelty measure behaves more reliably and captures more the "high risk" nature of novel research.

\section{Discussion}

We propose that a way to measure the potential an article has to advance the knowledge frontier is to examine the combinatorial novelty of its references. To this end, we apply a newly minted measure of novelty to all WoS research articles published in 2001 across all scientific disciplines. We find that novel papers, in particular highly novel papers, exhibit citation patterns consistent with the "high risk/high gain" profile associated with breakthrough research. Novel papers have a higher variance in citation performance than do non-novel papers, confirming their risky profile. At the same time, novel papers are associated with big hits. They have a much higher chance of being top $1 \%$ highly cited, and are more likely to lead to follow-up high impact 
research. Novel papers also have a broader impact across scientific fields, and are more likely to be highly cited in foreign fields compared with non-novel papers but not more likely to be highly cited in their home fields. Furthermore, novel papers require a sufficient period of time before their important contribution is recognized. This delayed recognition is suggestive of reluctance from incumbent scientific paradigms to recognize novel approaches and the longer time period needed to incorporate novel research into subsequent research. Part of the delayed recognition is due to the time it takes for novel research to diffuse to other fields, where they have their greatest impact.

Delayed recognition leads novel research to perform poorly on classic bibliometric measures which use short citation windows. Novel research is also published in journals with lower than expected Impact Factors, another classic bibliometric measure. Moreover, even if novel research succeeds in being published in high impact factor journals, it still suffers from delayed recognition.

Taken together, our results suggest that standard bibliometric measures are biased against novel research and thus may fail to identify papers and individuals doing novel research. This bias against novelty imperils scientific progress, because novel research, as we have shown, is much more likely to become a big hit in the long run in fields outside its own, as well as to stimulate follow-up big hits.

The bias against novelty is of particular concern given the increased reliance funding agencies place on classic bibliometric indicators in making funding and evaluation decisions. The bias against novel papers may also help explain why funding agencies which increasingly rely on bibliometric measures are widely perceived as being more and more risk-averse, choosing "safe" projects over those that involve a higher level of uncertainty with regard to possible outcomes. In this respect, our research is consistent with that of Boudreau et al. (forthcoming) who find that evaluators give lower scores to proposals that are highly novel where novelty is measured in terms of the proposal's use of novel combinations of MeSH terms relative to the underlying literature.

The bias against novelty applies not only to funding decisions but to science policy more generally. The prevailing use in various decisions (e.g., hiring and tenure of researchers) at 
various levels (i.e., department, university, and national) of standard bibliometric indicators which rely on short citation time windows and Journal Impact Factor is likely to disincentivize novel research. We advocate the awareness of such potential bias and suggest, when relying on bibliometric indicators, to use a wider portfolio of indicators and, when using standard measures, time windows beyond two or three years.

In addition, the finding that novel papers are highly cited in foreign fields but not in their home field highlights the importance of avoiding a monodisciplinary approach in peer review. Peer review is widely implemented in science decision-making. It is typically organized along disciplinary lines, with peers within the same discipline making a judgment on the value of the research that is being evaluated. Studies of interdisciplinary research demonstrate that a discipline-based science system is detrimental to the advancement and societal accountability of science (Gibbons, 1994; The National Academies, 2004). This paper contributes to this discussion, suggesting that peer review which is bounded by disciplinary boarders may fail to recognize the full value of novel research which typically lies outside its own field. 

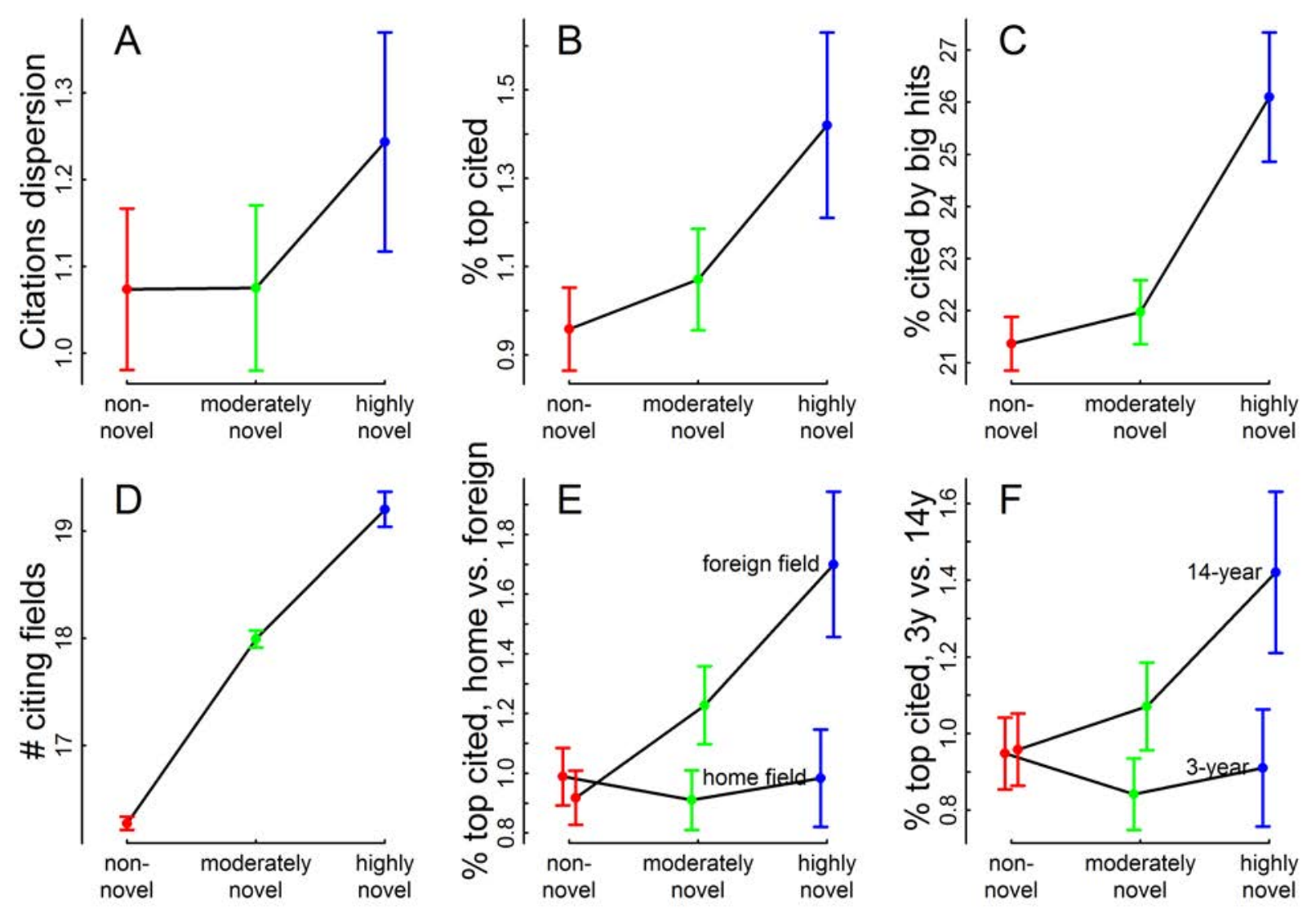

Figure 1. Impact profile of novel research. (A) Estimated dispersion of citations (14-year), based on the Generalized Negative Binomial model in Table 2 column 3. (B) Estimated probability of being among the top $1 \%$ cited articles in the same WoS subject category and publication year, based on 14-year citations and the logit model in Table 4 column 1. (C) Estimated probability of being cited by big hits, based on the logit model in Table 4 column 2. (D) Estimated number of WoS subject categories citing the focal paper (14-year), based on the Poisson model in Table 4 column 3. (E) Estimated probability of being among the top 1\% cited articles in the same WoS subject category and publication year, based on 14-year home and foreign field citations separately. Estimations are based on two logit models in Table 4 column 5 and 6. (F) Estimated probability of being among the top 1\% cited articles in the same WoS subject category and publication year, based on 3-year and 14-year citations separately. Estimations are based on two logit models in Table 5 column 3 and 14. All estimated values are for an average paper (i.e., in the biggest WoS subject category, not internationally coauthored, and with all other covariates at their means) in different novel classes. The vertical bars represent the 95\% confidence interval. Data consist of 1,056,936 WoS articles published in 2001 and are sourced from Thomson Reuters Web of Science Core Collection. 

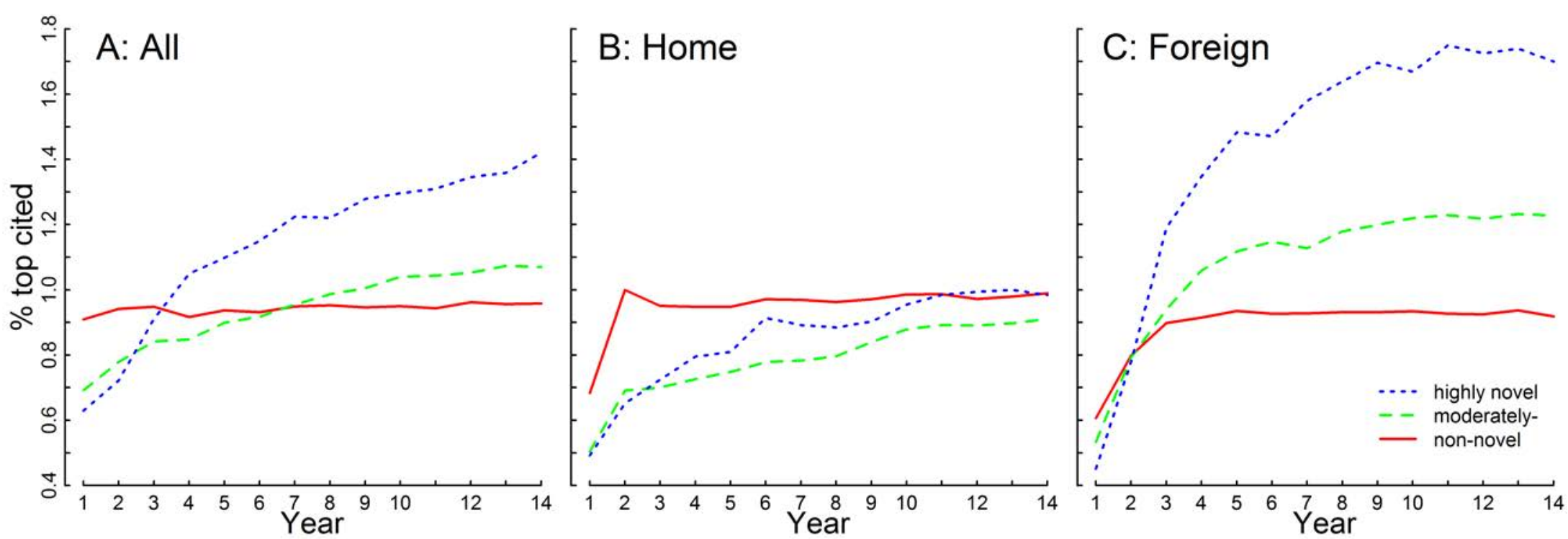

Figure 2. Citation dynamics and novelty. (A) Estimated probability of big hits, using 14 consecutive time windows to dynamically identify big hits. As an example, big hits in year 3 are identified as the top $1 \%$ highly cited papers based on their cumulative citations in a 3-year time window, i.e., from 2001 to 2003. Results are based on 14 logistic models reported in Table 5. (B) Estimated probability of big hits, based on home field citations, i.e., citations received from papers sharing at least one common WoS subject category with the focal cited paper. Results are based on 14 logistic models reported in Table A5. (C) Estimated probability of big hits, based on foreign field citations, i.e., citations received from papers sharing no common WoS subject categories with the focal cited paper. Results are based on 14 logistic models reported in Table A6. Data consist of 1,056,936 WoS articles published in 2001 and are sourced from Thomson Reuters Web of Science Core Collection. 


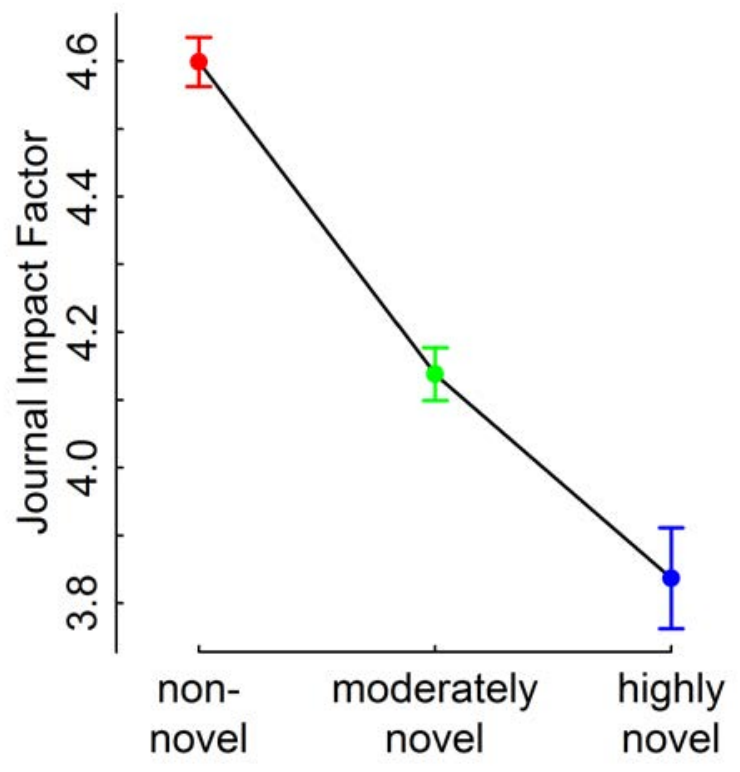

Figure 3. Journal Impact Factor and novelty. Estimated Journal Impact Factor for an average paper with different novelty classes, based on the Poisson model reported in Table 6 column 3. Data consist of 1,056,936 WoS articles published in 2001 and are sourced from Thomson Reuters Web of Science Core Collection. 


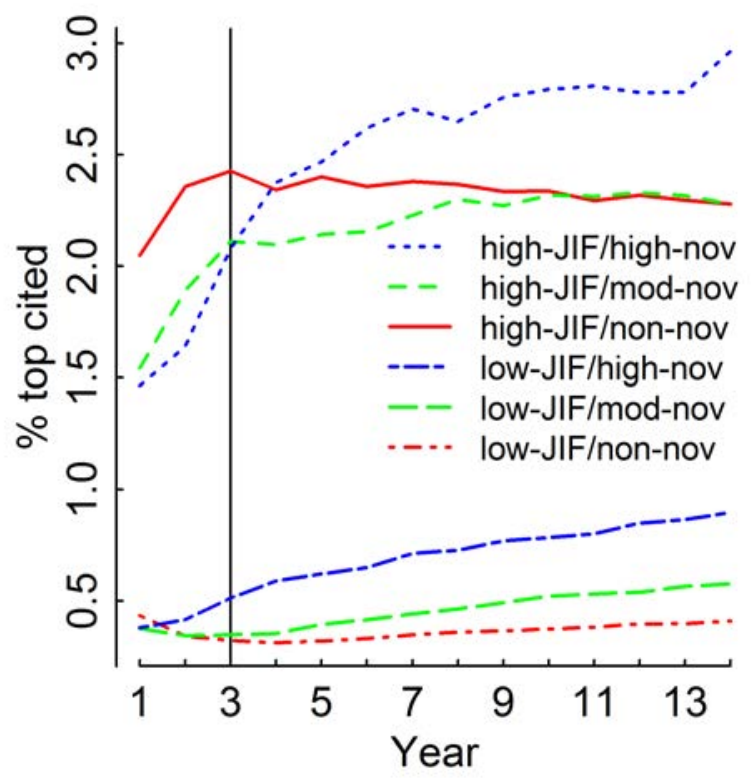

Figure 4. Citation dynamics and novelty, by JIF groups. Estimated probability of being a big hit by year, for papers in different novelty classes and Journal Impact Factor groups.

Estimations are based on a set of logistic models additionally incorporating interaction effects between novelty classes and whether a journal has an Impact Factor among the top 10\% in its field. Regression outputs are reported in Appendix II Table A7. Data consist of 1,056,936 WoS articles published in 2001 and are sourced from Thomson Reuters Web of Science Core Collection. 
Table 1. Occurrence of novelty

\begin{tabular}{lrrrrrr}
\hline & $\begin{array}{r}(1) \\
\text { Number of } \\
\text { papers }\end{array}$ & $\begin{array}{r}\text { \% of all } \\
\text { papers }\end{array}$ & $\begin{array}{r}\text { Avg (avg } \\
\text { cos) }\end{array}$ & $\begin{array}{r}(4) \\
\text { Avg(min } \\
\text { cos) }\end{array}$ & $\begin{array}{r}\text { Avg \# new } \\
\text { pairs }\end{array}$ & $\begin{array}{r}\text { Median \# } \\
\text { new pairs }\end{array}$ \\
\hline non-novel & 942850 & $89 \%$ & $/$ & $/$ & $/$ & $/$ \\
moderately novel & 103418 & $10 \%$ & 0.0015 & 0.0013 & 1.7055 & 1 \\
highly novel & 10668 & $1 \%$ & 0.0009 & 0.0004 & 7.9499 & 7 \\
\hline
\end{tabular}

Data sourced from Thomson Reuters Web of Science Core Collection. 
Table 2. Mean and dispersion of citations

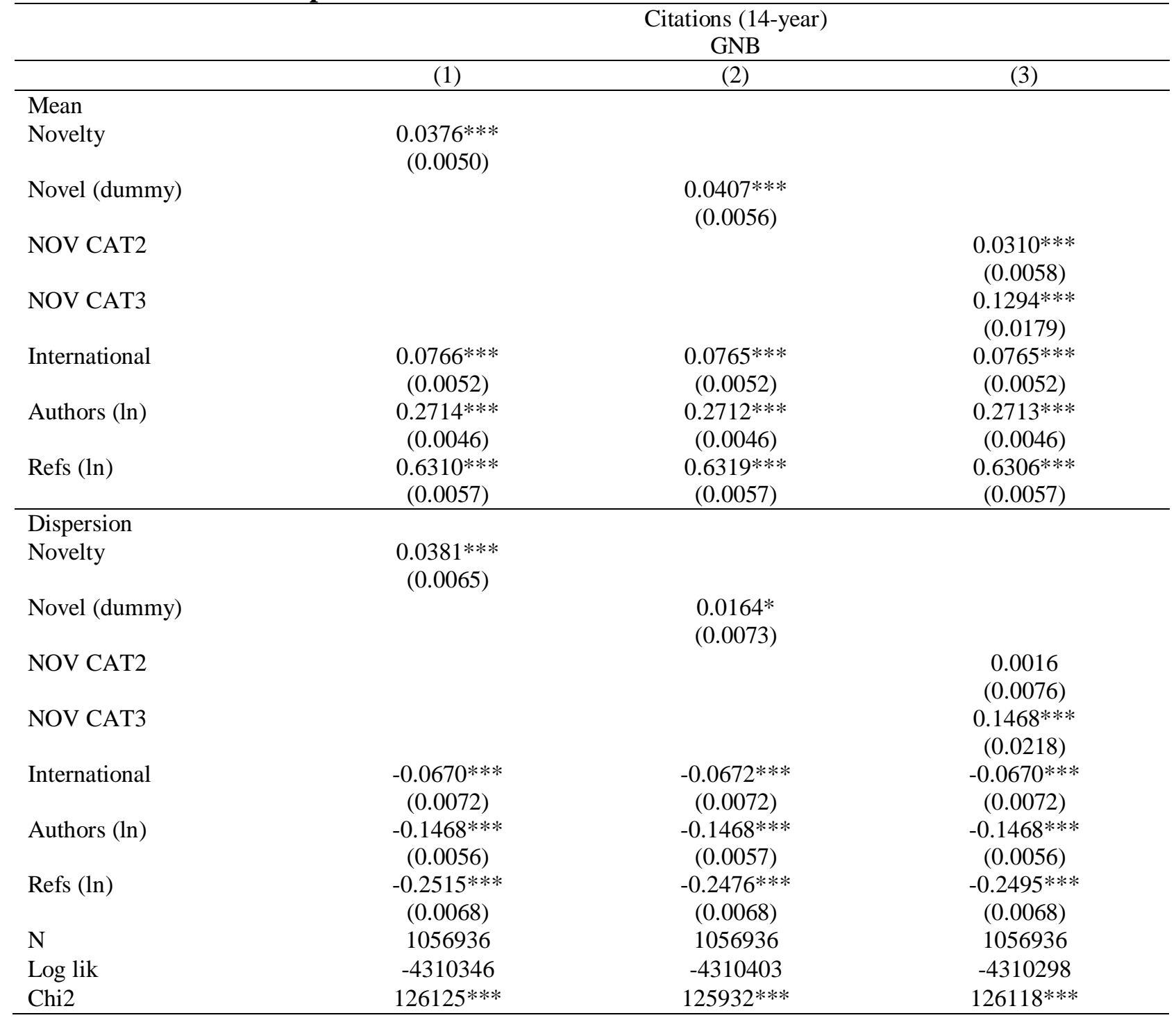

Data consist of all WoS articles published in 2001 and are sourced from Thomson Reuters Web of Science Core Collection. Field (WoS subject category) fixed effects incorporated. Robust standard errors in parentheses. ${ }^{* * *} \mathrm{p}<.001,{ }^{* *} \mathrm{p}<.01,{ }^{*} \mathrm{p}<.05,+\mathrm{p}<.10$. 
Table 3. Citation classes

\begin{tabular}{lc}
\hline & $\begin{array}{c}\text { Citation classes (14-year) } \\
\text { Multinomial logit }\end{array}$ \\
\hline Top 10\% vs. middle 80\% & $0.0567^{* * *}$ \\
NOV CAT2 & $(0.0103)$ \\
NOV CAT3 & $0.1680^{* * *}$ \\
& $(0.0258)$ \\
International & $0.0846^{* * *}$ \\
& $(0.0083)$ \\
Authors (ln) & $0.4607^{* * *}$ \\
& $(0.0063)$ \\
Refs (ln) & $1.0592^{* * *}$ \\
& $(0.0068)$ \\
Low 10\% vs. middle 80\% & \\
NOV CAT2 & $-0.0562^{* *}$ \\
NOV CAT3 & $(0.0163)$ \\
International & $0.1676^{* *}$ \\
Authors (ln) & $(0.0557)$ \\
Refs (ln) & $-0.2372^{* * *}$ \\
\hline N & $(0.0126)$ \\
Chi2 & $-0.5983^{* * *}$ \\
\hline
\end{tabular}

Data consist of all WoS articles published in 2001 and are sourced from Thomson Reuters Web of Science Core Collection. We classify papers, within the same WoS subject category and publication year, into three classes based on their 14-year citations: low $10 \%$, middle $80 \%$, and top $10 \%$. For the multinomial logit regression, the middle $80 \%$ is used as the reference group. Field (WoS subject category) fixed effects incorporated. Robust standard errors in parentheses. *** $\mathrm{p}<.001, * * \mathrm{p}<.01, * \mathrm{p}<.05,+\mathrm{p}<.10$. 
Table 4. Impact profile of novel research

\begin{tabular}{|c|c|c|c|c|c|c|}
\hline & $\begin{array}{c}\text { (1) } \\
\text { Top 1\% cited } \\
\text { (14-year) } \\
\text { logit }\end{array}$ & $\begin{array}{c}(2) \\
\text { Cited by big } \\
\text { hits } \\
\text { (9-year) } \\
\text { logit }\end{array}$ & $\begin{array}{c}\text { (3) } \\
\text { \# citing fields } \\
\text { (14-year) } \\
\text { Poisson }\end{array}$ & $\begin{array}{c}\text { (4) } \\
\text { Ratio foreign } \\
\text { field citations } \\
\text { (14-year) } \\
\text { OLS }\end{array}$ & $\begin{array}{c}\text { (5) } \\
\text { Top 1\% cited } \\
\text { home field } \\
\text { (14-year) } \\
\text { logit }\end{array}$ & $\begin{array}{c}\text { (6) } \\
\text { Top 1\% cited } \\
\text { foreign field } \\
\text { (14-year) } \\
\text { logit }\end{array}$ \\
\hline NOV CAT2 & $\begin{array}{c}0.1122^{* * *} \\
(0.0287)\end{array}$ & $\begin{array}{c}0.0356^{* *} \\
(0.0110)\end{array}$ & $\begin{array}{c}0.1005^{* * *} \\
(0.0013)\end{array}$ & $\begin{array}{c}0.0489 * * * \\
(0.0009)\end{array}$ & $\begin{array}{c}-0.0837 * * \\
(0.0307)\end{array}$ & $\begin{array}{c}0.2939^{* * *} \\
(0.0279)\end{array}$ \\
\hline NOV CAT3 & $\begin{array}{c}0.3982 * * * \\
(0.0593)\end{array}$ & $\begin{array}{c}0.2620 * * * \\
(0.0292)\end{array}$ & $\begin{array}{c}0.1656 * * * \\
(0.0039)\end{array}$ & $\begin{array}{c}0.0821^{* * *} * \\
(0.0025)\end{array}$ & $\begin{array}{l}-0.0052 \\
(0.0706)\end{array}$ & $\begin{array}{c}0.6237 * * * \\
(0.0563)\end{array}$ \\
\hline $\begin{array}{l}\text { 9-year } \\
\text { citations (ln) }\end{array}$ & & $\begin{array}{c}1.8363 * * * \\
(0.0051)\end{array}$ & & & & \\
\hline $\begin{array}{l}\text { 14-year } \\
\text { citations (ln) }\end{array}$ & & & $\begin{array}{c}0.5548^{* * *} \\
(0.0007)\end{array}$ & $\begin{array}{c}0.0030 * * * \\
(0.0003)\end{array}$ & & \\
\hline International & $\begin{array}{c}0.0681^{* *} \\
(0.0240)\end{array}$ & $\begin{array}{c}0.0037 \\
(0.0089)\end{array}$ & $\begin{array}{c}-0.0120 * * * \\
(0.0011)\end{array}$ & $\begin{array}{c}-0.0054^{* * *} \\
(0.0007)\end{array}$ & $\begin{array}{c}0.0801^{* *} \\
(0.0243)\end{array}$ & $\begin{array}{l}0.0600^{*} \\
(0.0245)\end{array}$ \\
\hline Authors (ln) & $\begin{array}{c}0.5539 * * * \\
(0.0182)\end{array}$ & $\begin{array}{c}-0.0648 * * * \\
(0.0066)\end{array}$ & $\begin{array}{c}0.0022^{*} \\
(0.0009)\end{array}$ & $\begin{array}{c}0.0122 * * * \\
(0.0005)\end{array}$ & $\begin{array}{c}0.5177 * * * \\
(0.0183)\end{array}$ & $\begin{array}{c}0.5436 * * * \\
(0.0184)\end{array}$ \\
\hline Refs (ln) & $\begin{array}{c}1.2074 * * * \\
(0.0206)\end{array}$ & $\begin{array}{c}-0.1143 * * * \\
(0.0071)\end{array}$ & $\begin{array}{c}0.0107 * * * \\
(0.0010)\end{array}$ & $\begin{array}{c}0.0062^{* * *} \\
(0.0005)\end{array}$ & $\begin{array}{c}1.2136^{* * *} \\
(0.0206)\end{array}$ & $\begin{array}{c}1.1586 * * * \\
(0.0208)\end{array}$ \\
\hline $\mathrm{N}$ & 1056929 & 1056565 & 1056918 & 990479 & 1056146 & 1056146 \\
\hline Log lik & -56424 & -266709 & -2635145 & l & -55156 & -54878 \\
\hline Chi2 & $5445^{* * *}$ & $145503 * * *$ & $1746164 * * *$ & l & $4823 * * *$ & $5518 * * *$ \\
\hline R2 & I & I & I & 0.1276 & I & \\
\hline
\end{tabular}

Data consist of all WoS articles published in 2001 and are sourced from Thomson Reuters Web of Science Core Collection. Top 1\% cited (column 1) means being among the top 1\% highly cited within the same WoS subject category and publication year, based on the number of citations in a 14-year time window between 2001 and 2014. Cited by big hit (column 2) means cited by an article, which is published in between 2001 and 2009 and among the top 1\% highly cited articles within the same WoS subject category and publication year, based on their cumulative citations up to 2014. Big hits published after 2009 are not analysed because their available time windows are too short to identify big hits reliably. \# citing fields (column 3 ) is the number of WoS subject categories citing the focal paper. Ratio foreign field citations (column 4) is the proportion of all citations that are from papers sharing no common WoS subject categories with the focal cited paper. Top 1\% cited home field (column 5) means being among the top 1\% highly cited within the same WoS subject category and publication year, based on 14-year citation received from papers that share at least one common WoS subject category with the focal cited paper. Top 1\% cited foreign field (column 6) means being among the top 1\% highly cited within the same WoS subject category and publication year, based on 14-year citation received from papers that share no common WoS subject category with the focal cited paper. Field (WoS subject category) fixed effects incorporated. Robust standard errors in parentheses. $* * * \mathrm{p}<.001, * * \mathrm{p}<.01, * \mathrm{p}<.05,+\mathrm{p}<.10$. 
Table 5. Big hits and novelty: Delayed recognition

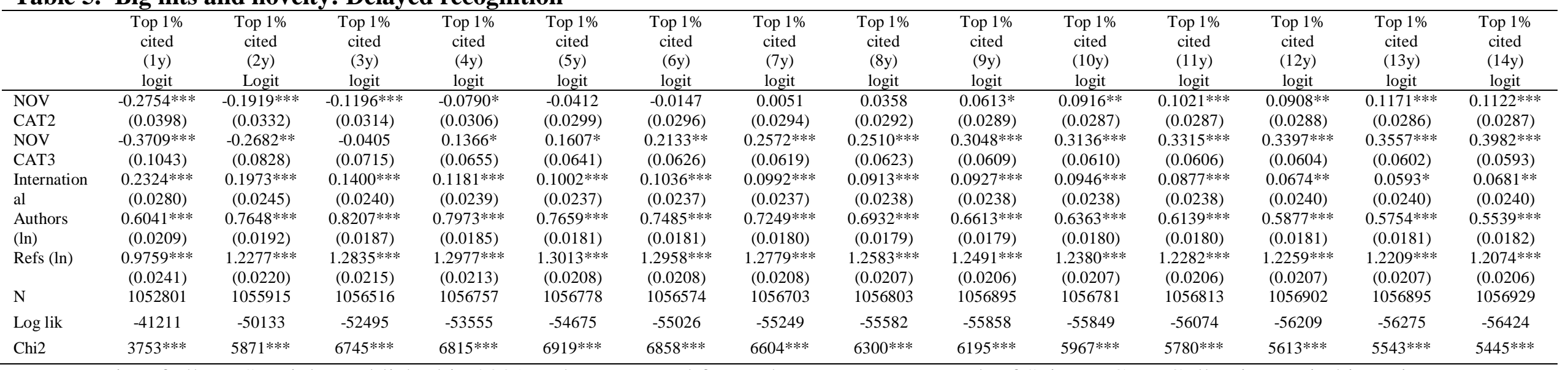

Data consist of all WoS articles published in 2001 and are sourced from Thomson Reuters Web of Science Core Collection. Big hits using a $t$-year time window means among the top $1 \%$ highly cited papers within the same WoS subject category and publication year, based on their citations in the $t$-year time window starting from 2001. Identifying big hits using annual citation counts instead of cumulative citation counts yields similar results. Field (WoS subject category) fixed effects incorporated. Robust standard errors in parentheses. ${ }^{* * *} \mathrm{p}<.001, * * \mathrm{p}<.01, * \mathrm{p}<.05,+\mathrm{p}<.10$. 
Table 6. Journal Impact Factor and novelty

\begin{tabular}{|c|c|c|c|c|c|c|c|c|}
\hline & $\begin{array}{c}\text { (1) } \\
\text { Journal age } \\
\text { Poisson }\end{array}$ & $\begin{array}{c}(2) \\
\text { Jnl Age <4 } \\
\text { logit }\end{array}$ & $\begin{array}{c}\text { (3) } \\
\text { JIF } \\
\text { Poisson }\end{array}$ & $\begin{array}{c}\text { (4) } \\
\text { JIF } \\
\text { Poisson }\end{array}$ & $\begin{array}{c}\text { (5) } \\
\text { JIF } \\
\text { Poisson }\end{array}$ & $\begin{array}{c}(6) \\
\text { JIF TOP } 10 \% \\
\text { logit }\end{array}$ & $\begin{array}{c}(7) \\
\text { JIF TOP } 10 \% \\
\text { logit }\end{array}$ & $\begin{array}{c}\text { (8) } \\
\text { JIF TOP 10\% } \\
\text { logit }\end{array}$ \\
\hline NOV CAT2 & $\begin{array}{c}-0.0781^{* * *} \\
(0.0027)\end{array}$ & $\begin{array}{c}0.1119 * * * \\
(0.0145)\end{array}$ & $\begin{array}{c}-0.1055^{* * *} \\
(0.0031)\end{array}$ & $\begin{array}{c}-0.0839 * * * \\
(0.0031)\end{array}$ & $\begin{array}{c}-0.1033 * * * \\
(0.0031)\end{array}$ & $\begin{array}{c}-0.2013 * * * \\
(0.0093)\end{array}$ & $\begin{array}{c}-0.1551^{* * *} \\
(0.0094)\end{array}$ & $\begin{array}{c}-0.1984 * * * \\
(0.0093)\end{array}$ \\
\hline NOV CAT3 & $\begin{array}{c}-0.1673^{* * *} \\
(0.0079)\end{array}$ & $\begin{array}{c}0.3551^{* * *} \\
(0.0388)\end{array}$ & $\begin{array}{c}-0.1811^{* * *} \\
(0.0092)\end{array}$ & $\begin{array}{c}-0.1352^{* * *} \\
(0.0088)\end{array}$ & $\begin{array}{c}-0.1744^{* * *} \\
(0.0091)\end{array}$ & $\begin{array}{c}-0.3897 * * * \\
(0.0268)\end{array}$ & $\begin{array}{c}-0.2767 * * * \\
(0.0273)\end{array}$ & $\begin{array}{c}-0.3794 * * * \\
(0.0269)\end{array}$ \\
\hline $\begin{array}{l}\text { Journal age } \\
\text { (ln) }\end{array}$ & & & & $\begin{array}{c}0.2211^{* * *} \\
(0.0013)\end{array}$ & & & $\begin{array}{c}0.6778 * * * \\
(0.0046)\end{array}$ & \\
\hline Journal age $<4$ & & & & & $\begin{array}{c}-0.3421^{* * *} \\
(0.0048)\end{array}$ & & & $\begin{array}{c}-0.5875^{* * *} \\
(0.0150)\end{array}$ \\
\hline International & $\begin{array}{c}0.0357 * * * \\
(0.0019)\end{array}$ & $\begin{array}{c}-0.0835 * * * \\
(0.0117)\end{array}$ & $\begin{array}{c}0.0737 * * * \\
(0.0024)\end{array}$ & $\begin{array}{c}0.0651 * * * \\
(0.0023)\end{array}$ & $\begin{array}{c}0.0724 * * * \\
(0.0023)\end{array}$ & $\begin{array}{c}0.1309 * * * \\
(0.0069)\end{array}$ & $\begin{array}{c}0.1122 * * * \\
(0.0070)\end{array}$ & $\begin{array}{c}0.1289 * * * \\
(0.0069)\end{array}$ \\
\hline Authors (ln) & $\begin{array}{c}0.0413 * * * \\
(0.0013)\end{array}$ & $\begin{array}{c}-0.1191 * * * \\
(0.0078)\end{array}$ & $\begin{array}{c}0.1735^{* * * *} \\
(0.0018)\end{array}$ & $\begin{array}{c}0.1602 * * * \\
(0.0017)\end{array}$ & $\begin{array}{c}0.1712 * * * \\
(0.0018)\end{array}$ & $\begin{array}{c}0.4529 * * * \\
(0.0051)\end{array}$ & $\begin{array}{c}0.4366 * * * \\
(0.0052)\end{array}$ & $\begin{array}{c}0.4499 * * * \\
(0.0051)\end{array}$ \\
\hline Refs (ln) & $\begin{array}{c}0.1091 * * * \\
(0.0013)\end{array}$ & $\begin{array}{c}-0.1366 * * * \\
(0.0072)\end{array}$ & $\begin{array}{c}0.3519 * * * \\
(0.0017)\end{array}$ & $\begin{array}{c}0.3250 * * * \\
(0.0016)\end{array}$ & $\begin{array}{c}0.3496 * * * \\
(0.0017)\end{array}$ & $\begin{array}{c}0.8863 * * * \\
(0.0053)\end{array}$ & $\begin{array}{c}0.8446^{* * *} \\
(0.0054)\end{array}$ & $\begin{array}{c}0.8836^{* * *} \\
(0.0053)\end{array}$ \\
\hline $\mathrm{N}$ & 1056936 & 1029027 & 1056936 & 1056936 & 1056936 & 1054940 & 1054940 & 1054940 \\
\hline Log lik & -8153953 & -220326 & -1716396 & -1680856 & -1711208 & -428264 & -411420 & -427354 \\
\hline Chi2 & $191087 * * *$ & $23417 * * *$ & $942910 * * *$ & $1169732^{* * *}$ & $966429 * * *$ & $78384 * * *$ & $92594 * * *$ & $78492 * * *$ \\
\hline
\end{tabular}

Data consist of all WoS articles published in 2001 and are sourced from Thomson Reuters Web of Science Core Collection. Results of Poisson models are reported here, an alternative specification, using the OLS model and the log of journal age or JIF as the dependent variable yields consistent results. Field (WoS subject category) fixed effects incorporated. Robust standard errors in parentheses. $* * * \mathrm{p}<.001, * * \mathrm{p}<.01, * \mathrm{p}<.05,+\mathrm{p}<.10$. 


\section{References}

Adams, J. D., Black, G. C., Clemmons, J. R., \& Stephan, P. E. (2005). Scientific teams and institutional collaborations: Evidence from US universities, 1981-1999. Research Policy, 34(3), 259-285. doi:10.1016/j.respol.2005.01.014

Alberts, B. (2010). Overbuilding Research Capacity. Science, 329(5997), 1257-1257. doi:10.1126/science.1197077

Arrow, K. (1962). Economic welfare and the allocation of resources for invention The rate and direction of inventive activity: Economic and social factors (pp. 609-626): Princeton University Press.

Arthur, W. B. (2009). The nature of technology: what it is and how it evolves. New York: Free Press.

Azoulay, P., Graff Zivin, J. S., \& Manso, G. (2011). Incentives and creativity: evidence from the academic life sciences. The RAND Journal of Economics, 42(3), 527-554. doi:10.1111/j.17562171.2011.00140.x

Azoulay, P., Güler, I., Koçak, Ö., Murciano-Goroff, R., \& Anttila-Hughes, J. (2012). Are recombinant scientific articles more impactful?

Bornmann, L., Leydesdorff, L., \& Wang, J. (2014). How to improve the prediction based on citation impact percentiles for years shortly after the publication date? Journal of Informetrics, 8(1), 175180. doi:10.1016/j.joi.2013.11.005

Boudreau, K. J., Guinan, E. C., Lakhani, K. R., \& Riedl, C. (forthcoming). Looking Across and Looking Beyond the Knowledge Frontier: Intellectual Distance, Novelty, and Resource Allocation in Science. Management Science, O(0), null. doi:doi:10.1287/mnsc.2015.2285

Boyack, K. W., \& Klavans, R. (2014). Atypical combinations are confounded by disciplinary effects. STI 2014 Leiden, 64.

Burt, R. S. (2004). Structural holes and good ideas. American Journal of Sociology, 110(2), 349-399. doi:10.1086/421787

Butler, L. (2003). Explaining Australia's increased share of ISI publications - the effects of a funding formula based on publication counts. Research Policy, 32(1), 143-155. doi:10.1016/s00487333(02)00007-0

Carroll, S. B. (2013). Brave genius : a scientist, a philosopher, and their daring adventures from the French resistance to the Nobel Prize (First edition. ed.). New York: Crown Publishers.

Cook, G. (2015, January 11). Sebastian Seung's Quest to Map the Human Brain. The New York Times Magazine, MM27.

Denk, W., \& Horstmann, H. (2004). Serial block-face scanning electron microscopy to reconstruct threedimensional tissue nanostructure. Plos Biology, 2(11), 1900-1909. doi:10.1371/journal.pbio.0020329

Fleming, L. (2001). Recombinant uncertainty in technological search. Management Science, 47(1), 117132. doi:10.1287/mnsc.47.1.117.10671

Fleming, L. (2007). Breakthroughs and the "Long tail" of innovation. Mit Sloan Management Review, 49(1), 69-74. Retrieved from <Go to ISI $>$ ://WOS:000250326600014

Garfield, E. (1980). Premature discovery or delayed recognition-Why. Current Contents, 21, 5-10.

Gibbons, M. (1994). The new production of knowledge: Sage Publ.

Hicks, D. (2004). The Four Literatures of Social Science. In H. F. Moed, W. Glänzel, \& U. Schmoch (Eds.), Handbook of quantitative science and technology research. New York: Springer.

Hicks, D. (2012). Performance-based university research funding systems. Research Policy, 41(2), 251261. doi:10.1016/j.respol.2011.09.007

Hicks, D., Wouters, P., Waltman, L., de Rijcke, S., \& Rafols, I. (2015). The Leiden Manifesto for research metrics. Nature, 520, 429-431.

Kaiser, D. (2009). Drawing theories apart: The dispersion of Feynman diagrams in postwar physics: University of Chicago Press. 
Katz, J. S., \& Hicks, D. (1997). How much is a collaboration worth? A calibrated bibliometric model. Scientometrics, 40(3), 541-554. Retrieved from $<$ Go to ISI $>$ ://000071723600016

Kolata, G. (2009, June 27, 2009). Grant System Leads Cancer Researchers to Play It Safe. New York Times. Retrieved from http://www.nytimes.com/2009/06/28/health/research/28cancer.html

Kuhn, T. S. (1962). The structure of scientific revolutions. Chicago, IL: University of Chicago Press.

Lee, Y.-N., Walsh, J. P., \& Wang, J. (2015). Creativity in scientific teams: Unpacking novelty and impact. Research Policy, 44(3), 684-697. doi:http://dx.doi.org/10.1016/j.respol.2014.10.007

March, J. G. (1991). Exploration and exploitation in organizational learning. Organization Science, 2(1), 71-87. doi:10.1287/orsc.2.1.71

Martin, B. R. (2016). Editors' JIF-boosting stratagems - Which are appropriate and which not? Research Policy, 45(1), 1-7. doi:http://dx.doi.org/10.1016/j.respol.2015.09.001

Mednick, S. A. (1962). The associative basis of the creative process. Psychological Review, 69(3), 220232. doi:10.1037/h0048850

Merton, R. K. (1973). The sociology of science. Chicago, IL: University of Chicago Press.

Monastersky, R. (2005). The number that's devouring science. Chronicle of Higher Education, 52(8), 14.

Nelson, R. R., \& Winter, S. G. (1982). An Evolutionary Theory of Economic Change. Cambridge, MA: Belknap Press of Harvard University Press.

NPR. (2013). Scientists win Nobel for work on how cells communicate. Retrieved from http://www.npr.org/templates/story/story.php?storyId=230192033

Petsko, G. A. (2012). Goodbye, Columbus. Genome Biology, 13(5). doi:10.1186/gb-2012-13-5-155

Planck, M. (1950). Scientific autobiography, and other papers. London,: Williams \& Norgate.

Rinia, E., Van Leeuwen, T., Bruins, E., Van Vuren, H., \& Van Raan, A. (2002). Measuring knowledge transfer between fields of science. Scientometrics, 54(3), 347-362. doi:10.1023/A:1016078331752

Romer, P. M. (1994). The Origins of Endogenous Growth. The Journal of Economic Perspectives, 8(1), 3-22. Retrieved from http://www.jstor.org/stable/2138148

Schumpeter, J. A. (1939). Business Cycles; A Theoretical, Historical, and Statistical Analysis of the Capitalist Process (1st ed.). New York, London,: McGraw-Hill Book Company, inc.

Simonton, D. K. (2004). Creativity in Science: Chance, Logic, Genius, and Zeitgeist. Cambridge, UK; New York, NY: Cambridge University Press.

StataCorp. (2016). nbreg. Retrieved from http://www.stata.com/manuals13/rnbreg.pdf

The National Academies. (2004). Facilitating interdisciplinary research. Washington DC: The National Academies Press.

Uzzi, B., Mukherjee, S., Stringer, M., \& Jones, B. (2013). Atypical combinations and scientific impact. Science, 342(6157), 468-472. doi:10.1126/science.1240474

Varian, H. R. (2009). The Economics of Combinatorial Innovation. Guglielmo Marconi Lecture, Lisbon Council. Retrieved from http://www. youtube. com/watch

Verhoeven, D., Bakker, J., \& Veugelers, R. (2016). Measuring technological novelty with patent-based indicators. Research Policy, 45(3), 707-723. doi:http://dx.doi.org/10.1016/j.respol.2015.11.010

Walsh, D. (2013). Not Safe for Funding: The N.S.F. and the Economics of Science. The New Yorker. Retrieved from http://www.newyorker.com/tech/elements/not-safe-for-funding-the-n-s-f-and-theeconomics-of-science

Wang, J. (2013). Citation time window choice for research impact evaluation. Scientometrics, 94(3), 851872. doi:10.1007/s11192-012-0775-9

Wang, J., Thijs, B., \& Glänzel, W. (2015). Interdisciplinarity and impact: Distinct effects of variety, balance and disparity. Plos One, in press.

Weitzman, M. L. (1998). Recombinant Growth. The Quarterly Journal of Economics, 113(2), 331-360. Retrieved from http://www.jstor.org/stable/2586906

Wyatt, H. (1975). Knowledge and prematurity: the journey from transformation to DNA. Perspectives in Biology and Medicine, 18(2), 149-156. 


\section{Appendix I: Indicator illustration}

We use the paper coauthored by Denk and Horstmann (2004), "Serial Block-Face Scanning Electron Microscopy to Reconstruct Three-Dimensional Tissue Nanostructure” published in PLOS Biology to illustrate our novelty measure. This paper cites 19 WoS-indexed journals. Of all possible journal pairs (171), 9 journal pairs are new, using the procedure described supra.

\begin{tabular}{|l|l|l|l|}
\hline Pair & Journal 1 & Journal 2 & Novelty \\
\hline 1 & NATURE MATERIALS & CURRENT OPINION IN NEUROBIOLOGY & 0.9992 \\
\hline 2 & NATURE MATERIALS & DEVELOPMENTAL DYNAMICS & 0.9991 \\
\hline 3 & NATURE MATERIALS & $\begin{array}{l}\text { PHILOSOPHICAL TRANSACTIONS OF THE } \\
\text { ROYAL SOCIETY OF LONDON SERIES B- } \\
\text { BIOLOGICAL SCIENCES }\end{array}$ & 0.9984 \\
\hline 4 & NATURE MATERIALS & EUROPEAN JOURNAL OF NEUROSCIENCE & 0.9992 \\
\hline 5 & NATURE MATERIALS & JOURNAL OF HISTOTECHNOLOGY & 0.9986 \\
\hline 6 & NATURE MATERIALS & SCANNING & 0.9980 \\
\hline 7 & NATURE MATERIALS & BRAIN RESEARCH REVIEWS & 0.9994 \\
\hline 8 & NATURE MATERIALS & $\begin{array}{l}\text { ANNUAL REVIEW OF BIOPHYSICS AND } \\
\text { BIOENGINEERING }\end{array}$ & 0.9978 \\
\hline 9 & NATURE MATERIALS & $\begin{array}{l}\text { PFLUGERS ARCHIV-EUROPEAN JOURNAL OF } \\
\text { PHYSIOLOGY }\end{array}$ & 0.9992 \\
\hline
\end{tabular}

Each of these new journal pairs involves an article from Nature Materials (subject categories: Chemistry, Physical; Materials Science, Multidisciplinary; Physics, Applied; and Physics, Condensed Matter), being combined with articles from journals in subject categories of Neurosciences; Cell Biology; and Physiology. In the next step we calculate the cosine similarity for each journal pair, based on their profile of co-cited journals in the preceding three years (i.e., 2001-2003).

The co-citation matrix between all journals in the database is reported in the following table, based on the co-citation information in the preceding three years, i.e., 2001-2003. One entry represents the number of times that two corresponding journals are co-cited in the preceding three years. For example, NATURE MATERIALS has not been cited together with CURRENT OPINION IN NEUROBIOLOGY by any papers published between 2001 and 2003, but has been cited together with SCIENCE by 331 papers. 


\begin{tabular}{|l|r|r|r|r|r|r|r|}
\hline & $\mathrm{J}_{1}$ & $\mathrm{~J}_{2}$ & $\mathrm{~J}_{3}$ & $\mathrm{~J}_{4}$ & $\mathrm{~J}_{5}$ & $\ldots$ & $\mathrm{J}_{\mathrm{N}}$ \\
\hline $\mathrm{J}_{1}$ NATURE MATERIALS & $/$ & 0 & 331 & 110 & 0 & $\ldots$ & $\ldots$ \\
\hline $\mathrm{J}_{2}$ CURRENT OPINION IN NEUROBIOLOGY & 0 & $/$ & 9691 & 0 & 9959 & $\ldots$ & $\ldots$ \\
\hline $\mathrm{J}_{3}$ SCIENCE & 331 & 9691 & $/$ & $\ldots$ & $\ldots$ & $\ldots$ & $\ldots$ \\
\hline $\mathrm{J}_{4}$ NANO LETTERS & 110 & 0 & $\ldots$ & $/$ & $\ldots$ & $\ldots$ & $\ldots$ \\
\hline $\mathrm{J}_{5}$ JOURNAL OF NEUROSCIENCE & 0 & 9959 & $\ldots$ & $\ldots$ & $/$ & $\ldots$ & $\ldots$ \\
\hline$\ldots$ & $\ldots$ & $\ldots$ & $\ldots$ & $\ldots$ & $\ldots$ & $/$ & $\ldots$ \\
\hline $\mathrm{J}_{\mathrm{N}}$ & $\ldots$ & $\ldots$ & $\ldots$ & $\ldots$ & $\ldots$ & $\ldots$ & $/$ \\
\hline
\end{tabular}

Using the cosine similarity score, the ease of combining NATURE MATERIALS and CURRENT OPINION IN NEUROBIOLOGY is:

$$
\begin{aligned}
\operatorname{COS}_{1,2}=\frac{\mathrm{J}_{1} \cdot \mathrm{J}_{2}}{\left\|\mathrm{~J}_{1}\right\|\left\|\mathrm{J}_{2}\right\|}= & \frac{\sum \mathrm{J}_{1, \mathrm{i}} \times \mathrm{J}_{2, \mathrm{i}}}{\sqrt{\sum \mathrm{J}_{1, \mathrm{i}}^{2} \times \sum \mathrm{J}_{2, \mathrm{i}}^{2}}} \\
& =\frac{331 \times 9691+110 \times 0+0 \times 9959+\cdots}{\sqrt{\left(0^{2}+331^{2}+110^{2}+0^{2}+\cdots\right) \times\left(0^{2}+9691^{2}+0^{2}+9959^{2}+\cdots\right)}} \\
& =0.0008
\end{aligned}
$$

Correspondingly, the difficulty of making this combination is: $1-\operatorname{COS}_{1,2}=0.9992$. We calculate the difficulty of all the other journal combinations following the same procedure. At the paper level, we sum up these difficulty scores and get a novelty measure, novelty $=8.9891$, which places the paper in the top $1 \%$ of novel papers in its field. 


\section{Appendix II: Variables, descriptive statistics, and additional regressions}

\section{Table A1. List of variables}

\begin{tabular}{|c|c|c|}
\hline & Variable & Description \\
\hline 1 & Novelty & Continuous combinatorial novelty score. \\
\hline 2 & NOV CAT1 & $\begin{array}{l}\text { Novelty class dummy: } 1 \text { if non-novel, i.e., if a paper has no new } \\
\text { journal combinations, and } 0 \text { otherwise. }\end{array}$ \\
\hline 3 & NOV CAT2 & $\begin{array}{l}\text { Novelty class dummy: } 1 \text { if moderately novel, i.e., if a paper makes at } \\
\text { least one new combination but has a novelty score lower than the top } \\
1 \% \text { of its subject category, and } 0 \text { otherwise. }\end{array}$ \\
\hline 4 & NOV CAT3 & $\begin{array}{l}\text { Novelty class dummy: } 1 \text { if highly novel, i.e., if a paper has a novelty } \\
\text { score among the top } 1 \% \text { of its subject category, and } 0 \text { otherwise. }\end{array}$ \\
\hline 5 & Citations (14y) & $\begin{array}{l}\text { Cumulative number of citations in a 14-year tine window, i.e., 2001- } \\
2014 .\end{array}$ \\
\hline 6 & Top 1\% cited (14y) & $\begin{array}{l}\text { Dummy, } 1 \text { if among the top } 1 \% \text { cited in the same subject category, } \\
\text { based on } 14 \text {-year citations. }\end{array}$ \\
\hline 7 & Top 1\% cited (3y) & $\begin{array}{l}\text { Dummy, } 1 \text { if among the top } 1 \% \text { cited in the same subject category, } \\
\text { based on 3-year citations. }\end{array}$ \\
\hline 8 & Citing fields & The number of WoS subject categories citing the focal paper. \\
\hline 9 & Ratio of foreign field citations & $\begin{array}{l}\text { The proportion of citations that are from papers sharing no common } \\
\text { WoS subject categories, using a 14-year citation time window. }\end{array}$ \\
\hline 10 & Top $1 \%$ cited in home fields (14y) & $\begin{array}{l}\text { Dummy, } 1 \text { if among the top } 1 \% \text { cited in the same subject category, } \\
\text { based on } 14 \text {-year home field citations, i.e., citations received from } \\
\text { subsequent papers sharing at least one common WoS subject } \\
\text { categories. }\end{array}$ \\
\hline 11 & Top $1 \%$ cited in foreign fields (14y) & $\begin{array}{l}\text { Dummy, } 1 \text { if among the top } 1 \% \text { cited in the same subject category, } \\
\text { based on } 14 \text {-year foreign field citations, i.e., citations received from } \\
\text { subsequent papers sharing no common WoS subject categories. }\end{array}$ \\
\hline 12 & Cited by big hits (9y) & $\begin{array}{l}\text { Dummy: } 1 \text { if cited by a big hit published between } 2001 \text { and } 2009 \text {. The } \\
\text { citing big hits are identified as the top } 1 \% \text { highly cited article in the } \\
\text { same WoS subject category and publication year, based on their } \\
\text { cumulative citations till 2014. Only big hits published between } 2001 \\
\text { and } 2009 \text { are identified, so that each citing article has at least six years } \\
\text { to accumulate citations, for a reliable identification of citing big hit } \\
\text { articles. }\end{array}$ \\
\hline 13 & JIF & The Impact Factor of the journal where the focal paper is published in. \\
\hline 14 & International & Dummy: 1 if internationally co-authored, and 0 otherwise. \\
\hline 15 & Authors & The number of authors. \\
\hline 16 & References & The number of references. \\
\hline
\end{tabular}


Table A2. Descriptive statistics and Spearman correlations

\begin{tabular}{|c|c|c|c|c|c|c|c|c|c|c|c|c|c|c|c|c|c|c|c|c|}
\hline & Variable & Mean & Std. Dev. & Min & Max & 1 & 2 & 3 & 4 & 5 & 6 & 7 & 8 & 9 & 10 & 11 & 12 & 13 & 14 & 15 \\
\hline 1 & Novelty & 0.25 & 1.26 & 0 & 249 & & & & & & & & & & & & & & & \\
\hline 2 & NOV CAT1 & 0.89 & 0.31 & 0 & 1 & -1.00 & & & & & & & & & & & & & & \\
\hline 3 & NOV CAT2 & 0.10 & 0.30 & 0 & 1 & .93 & -.95 & & & & & & & & & & & & & \\
\hline 4 & NOV CAT3 & 0.01 & 0.10 & 0 & 1 & .32 & -.29 & -.03 & & & & & & & & & & & & \\
\hline 5 & Citations (14y) & 26.28 & 72.99 & 0 & 30068 & .11 & -.11 & .10 & .04 & & & & & & & & & & & \\
\hline 6 & Top $1 \%$ cited (14y) & 0.01 & 0.10 & 0 & 1 & .02 & -.02 & .02 & .02 & .17 & & & & & & & & & & \\
\hline 7 & Top 1\% cited (3y) & 0.01 & 0.10 & 0 & 1 & .01 & -.01 & .01 & .01 & .16 & .46 & & & & & & & & & \\
\hline 8 & Citing fields & 9.30 & 8.10 & 0 & 189 & .15 & -.15 & .14 & .06 & .86 & .15 & .13 & & & & & & & & \\
\hline 9 & Ratio of foreign field citations & 0.46 & 0.30 & 0 & 1 & .08 & -.08 & .07 & .03 & .07 & .02 & .01 & .26 & & & & & & & \\
\hline 10 & Top 1\% cited in home fields (14y) & 0.01 & 0.10 & 0 & 1 & .01 & -.01 & .01 & .01 & .17 & .66 & .40 & .14 & -.04 & & & & & & \\
\hline 11 & Top $1 \%$ cited in foreign fields (14y) & 0.01 & 0.10 & 0 & 1 & .03 & -.03 & .02 & .03 & .17 & .67 & .38 & .15 & .07 & .35 & & & & & \\
\hline 12 & Cited by big hits (9y) & 0.13 & 0.33 & 0 & 1 & .05 & -.05 & .04 & .03 & .43 & .24 & .20 & .38 & .04 & .23 & .22 & & & & \\
\hline 13 & JIF & 2.05 & 2.42 & 0 & 33 & .04 & -.04 & .04 & .01 & .53 & .08 & .09 & .47 & .07 & .08 & .07 & .24 & & & \\
\hline 14 & International & 0.19 & 0.39 & 0 & 1 & .01 & -.01 & .01 & .01 & .09 & .02 & .02 & .06 & .00 & .02 & .01 & .04 & .10 & & \\
\hline 15 & Authors & 4.10 & 6.18 & 1 & 743 & .02 & -.02 & .02 & .00 & .21 & .02 & .04 & .21 & .08 & .02 & .02 & .08 & .28 & .20 & \\
\hline 16 & References & 28.47 & 18.04 & 1 & 631 & .24 & -.24 & .21 & .10 & .39 & .06 & .06 & .35 & .07 & .05 & .06 & .16 & .32 & .06 & .02 \\
\hline
\end{tabular}

Data consist of all WoS articles published in 2001 and are sourced from Thomson Reuters Web of Science Core Collection. 
Table A3. Direct and direct impact of novel research

\begin{tabular}{lrrr}
\hline & NOV CAT1 & NOV CAT2 & NOV CAT3 \\
\hline \% being top 1\% cited (14-year) & $0.92 \%$ & $1.52 \%$ & $3.07 \%$ \\
Average citations of citing papers & 1.10 & 1.94 & 2.54 \\
Average JIF of citing papers & 0.15 & 0.25 & 0.31 \\
Probability of citing paper to be a top 1\% & $2.27 \%$ & $3.22 \%$ & $4.37 \%$ \\
$\quad$ paper (average annual '01-'09) & & & \\
Cited by big hits (9-year) & $12.03 \%$ & $16.63 \%$ & $22.08 \%$ \\
\hline
\end{tabular}

Data consist of all WoS articles published in 2001 and are sourced from Thomson Reuters Web of Science Core Collection. 
Table A4. Transdisciplinary impact of novel research

\begin{tabular}{|c|c|c|c|c|c|c|}
\hline & $\begin{array}{c}(1) \\
\text { \# citing fields } \\
\text { (14-year) }\end{array}$ & $\begin{array}{c}\text { (2) } \\
\text { \# citing fields } \\
\text { (14-year) }\end{array}$ & $\begin{array}{c}\text { (3) } \\
\text { \# citing fields } \\
\text { (14-year) }\end{array}$ & $\begin{array}{c}\text { (4) } \\
\text { Ratio foreign } \\
\text { field citations } \\
\text { (14-year) }\end{array}$ & $\begin{array}{c}\text { (5) } \\
\text { Ratio foreign } \\
\text { field citations } \\
\text { (14-year) }\end{array}$ & $\begin{array}{c}\text { (6) } \\
\text { Ratio foreign } \\
\text { field citations } \\
\text { (14-year) }\end{array}$ \\
\hline & Poisson & Poisson & Poisson & OLS & OLS & OLS \\
\hline NOV CAT2 & $\begin{array}{l}0.1005^{* * *} \\
(0.0013)\end{array}$ & $\begin{array}{l}0.0963 * * * \\
(0.0013)\end{array}$ & $\begin{array}{l}0.0979 * * * \\
(0.0013)\end{array}$ & $\begin{array}{l}0.0489 * * * \\
(0.0009)\end{array}$ & $\begin{array}{l}0.0530^{* * *} \\
(0.0009)\end{array}$ & $\begin{array}{l}0.0521^{* * *} \\
(0.0009)\end{array}$ \\
\hline NOV CAT3 & $\begin{array}{l}0.1656 * * * \\
(0.0039)\end{array}$ & $\begin{array}{l}0.1581 * * * \\
(0.0039)\end{array}$ & $\begin{array}{l}0.1611^{* * *} \\
(0.0039)\end{array}$ & $\begin{array}{l}0.0821^{* * *} \\
(0.0025)\end{array}$ & $\begin{array}{l}0.0902 * * * \\
(0.0025)\end{array}$ & $\begin{array}{l}0.0882 * * * \\
(0.0025)\end{array}$ \\
\hline $\begin{array}{l}\text { 14-year } \\
\text { citations (ln) }\end{array}$ & $\begin{array}{l}0.5548 * * * \\
(0.0007)\end{array}$ & $\begin{array}{l}0.5544 * * * \\
(0.0007)\end{array}$ & $\begin{array}{l}0.5550 * * * \\
(0.0007)\end{array}$ & $\begin{array}{l}0.0030 * * * \\
(0.0003)\end{array}$ & $\begin{array}{l}0.0038^{* * *} \\
(0.0003)\end{array}$ & $\begin{array}{l}0.0033 * * * \\
(0.0003)\end{array}$ \\
\hline $\begin{array}{l}\text { \# own fields } \\
\text { (ln) }\end{array}$ & & $\begin{array}{l}0.1075 * * * \\
(0.0010)\end{array}$ & & & $\begin{array}{l}-0.1082^{* * *} \\
(0.0006)\end{array}$ & \\
\hline $\begin{array}{l}\text { \# own fields > } \\
1\end{array}$ & & & $\begin{array}{l}0.0805^{* * *} \\
(0.0010)\end{array}$ & & & $\begin{array}{l}-0.0982 * * * \\
(0.0006)\end{array}$ \\
\hline International & $\begin{array}{l}-0.0120 * * * \\
(0.0011)\end{array}$ & $\begin{array}{l}-0.0118 * * * \\
(0.0011)\end{array}$ & $\begin{array}{l}-0.0119 * * * \\
(0.0011)\end{array}$ & $\begin{array}{l}-0.0054^{* * *} \\
(0.0007)\end{array}$ & $\begin{array}{l}-0.0055^{* * *} \\
(0.0007)\end{array}$ & $\begin{array}{l}-0.0055^{* * *} \\
(0.0007)\end{array}$ \\
\hline Authors (ln) & $\begin{array}{l}0.0022^{*} \\
(0.0009)\end{array}$ & $\begin{array}{l}0.0010 \\
(0.0009)\end{array}$ & $\begin{array}{l}0.0017+ \\
(0.0009)\end{array}$ & $\begin{array}{l}0.0122 * * * \\
(0.0005)\end{array}$ & $\begin{array}{l}0.0144^{* * *} \\
(0.0005)\end{array}$ & $\begin{array}{l}0.0135^{* * *} \\
(0.0005)\end{array}$ \\
\hline Refs (ln) & $\begin{array}{l}0.0107 * * * \\
(0.0010)\end{array}$ & $\begin{array}{l}0.0147 * * * \\
(0.0010)\end{array}$ & $\begin{array}{l}0.0126 * * * \\
(0.0010)\end{array}$ & $\begin{array}{l}0.0062 * * * \\
(0.0005)\end{array}$ & $\begin{array}{l}0.0022 * * * \\
(0.0005)\end{array}$ & $\begin{array}{l}0.0038 * * * \\
(0.0005)\end{array}$ \\
\hline $\mathrm{N}$ & 1056918 & 1056918 & 1056918 & 990479 & 990479 & 990479 \\
\hline Log lik & -2635145 & -2624447 & -2629356 & & & \\
\hline Chi2 & $1746164 * * *$ & $1757538 * * *$ & $1742435^{* * *}$ & & & \\
\hline R2 & & & & 0.1276 & 0.1525 & 0.1481 \\
\hline
\end{tabular}

Data consist of all WoS articles published in 2001 and are sourced from Thomson Reuters Web of Science Core Collection. \# citing fields (column 1-3) is the number of WoS subject categories citing the focal paper. Ratio foreign field citations (column 4-6) is the proportion of all citations that are from papers sharing no common WoS subject categories with the focal cited paper. \# own fields is the number of WoS subject categories that the focal paper itself is affiliated with. \# own fields $>1$ is a dummy variable, which takes 1 if the focal paper has more than 1 WoS subject categories and 0 if only one subject category. Field (WoS subject category) fixed effects incorporated. Robust standard errors in parentheses. ${ }^{* * *} \mathrm{p}<.001,{ }^{* *} \mathrm{p}<.01,{ }^{*} \mathrm{p}<.05,+\mathrm{p}<.10$. 
Table A5. Big hits in home fields

\begin{tabular}{|c|c|c|c|c|c|c|c|c|c|c|c|c|c|c|}
\hline & $\begin{array}{c}\text { Top 1\% } \\
\text { cited } \\
\text { (1y) } \\
\text { logit }\end{array}$ & $\begin{array}{c}\text { Top 1\% } \\
\text { cited } \\
\text { (2y) } \\
\text { Logit }\end{array}$ & $\begin{array}{c}\text { Top 1\% } \\
\text { cited } \\
\text { (3y) } \\
\text { logit }\end{array}$ & $\begin{array}{c}\text { Top 1\% } \\
\text { cited } \\
\text { (4y) } \\
\text { Logit }\end{array}$ & $\begin{array}{c}\text { Top 1\% } \\
\text { cited } \\
\text { (5y) } \\
\text { logit }\end{array}$ & $\begin{array}{c}\text { Top 1\% } \\
\text { cited } \\
\text { (6y) } \\
\text { logit }\end{array}$ & $\begin{array}{c}\text { Top 1\% } \\
\text { cited } \\
\text { (7y) } \\
\text { logit }\end{array}$ & $\begin{array}{c}\text { Top 1\% } \\
\text { cited } \\
\text { (8y) } \\
\text { logit }\end{array}$ & $\begin{array}{c}\text { Top 1\% } \\
\text { cited } \\
(9 y) \\
\text { logit }\end{array}$ & $\begin{array}{c}\text { Top 1\% } \\
\text { cited } \\
(10 y) \\
\text { logit }\end{array}$ & $\begin{array}{c}\text { Top 1\% } \\
\text { cited } \\
(11 \mathrm{y}) \\
\text { logit }\end{array}$ & $\begin{array}{c}\text { Top 1\% } \\
\text { cited } \\
(12 y) \\
\text { logit }\end{array}$ & $\begin{array}{c}\text { Top 1\% } \\
\text { cited } \\
\text { (13y) } \\
\text { logit }\end{array}$ & $\begin{array}{l}\text { Top 1\% } \\
\text { cited } \\
(14 y) \\
\text { logit }\end{array}$ \\
\hline NOV & $-0.3063 * * *$ & $-0.3728 * * *$ & $-0.3080^{* * *}$ & $-0.2689 * * *$ & $-0.2383 * * *$ & $-0.2224 * * *$ & $-0.2145^{* * *}$ & $-0.1917 * * *$ & $-0.1473^{* * *}$ & $-0.1152 * * *$ & $-0.1016^{* *}$ & $-0.0879 * *$ & $-0.0878^{* *}$ & $-0.0837 * *$ \\
\hline CAT2 & $(0.0423)$ & $(0.0369)$ & $(0.0343)$ & $(0.0333)$ & $(0.0327)$ & $(0.0325)$ & $(0.0321)$ & $(0.0318)$ & $(0.0314)$ & $(0.0311)$ & $(0.0309)$ & $(0.0308)$ & $(0.0308)$ & $(0.0307)$ \\
\hline NOV & $-0.3301^{* *}$ & $-0.4322 * * *$ & $-0.2748 * *$ & $-0.1773 *$ & $-0.1592 *$ & -0.0613 & -0.0834 & -0.0859 & -0.0729 & -0.0325 & -0.0018 & 0.0230 & 0.0208 & -0.0052 \\
\hline САТЗ & $(0.1105)$ & $(0.0933)$ & $(0.0811)$ & $(0.0764)$ & $(0.0751)$ & $(0.0723)$ & $(0.0725)$ & $(0.0722)$ & $(0.0720)$ & $(0.0713)$ & $(0.0705)$ & $(0.0699)$ & $(0.0700)$ & $(0.0706)$ \\
\hline Internation & $0.1933^{* * *}$ & $0.1796^{* * *}$ & $0.1521^{* * *}$ & $0.1317^{* * *}$ & $0.1231^{* * *}$ & $0.1154^{* * *}$ & $0.1163^{* * *}$ & $0.1130^{* * *}$ & $0.1057^{* * *}$ & $0.1016^{* * *}$ & $0.0899 * * *$ & $0.0946^{* * *}$ & $0.0833^{* *}$ & $0.0801^{* *}$ \\
\hline & $(0.0294)$ & $(0.0258)$ & $(0.0246)$ & $(0.0244)$ & $(0.0242)$ & $(0.0242)$ & $(0.0241)$ & $(0.0241)$ & $(0.0241)$ & $(0.0241)$ & $(0.0242)$ & $(0.0242)$ & $(0.0242)$ & $(0.0243)$ \\
\hline Authors & $0.4512^{* * *}$ & $0.6870^{* * *}$ & $0.7303^{* * *}$ & $0.7095^{* * *}$ & $0.6964 * * *$ & $0.6754^{* * *}$ & $0.6531 * * *$ & $0.6208^{* * *}$ & $0.6045^{* * *}$ & $0.5913^{* * *}$ & $0.5793^{* * *}$ & $0.5598^{* * *}$ & $0.5354^{* * *}$ & $0.5177^{* * *}$ \\
\hline $\begin{array}{l}\text { (ln) } \\
\text { Refs (ln) }\end{array}$ & $\begin{array}{c}(0.0235) \\
0.8235 * * *\end{array}$ & $\begin{array}{c}(0.0200) \\
1.1614 * * *\end{array}$ & $\begin{array}{c}(0.0189) \\
1.2466 * * *\end{array}$ & $\begin{array}{c}(0.0186) \\
1.2647 * * *\end{array}$ & $\begin{array}{c}(0.0183) \\
1.2622 * * *\end{array}$ & $\begin{array}{c}(0.0182) \\
1.2557 * * *\end{array}$ & $\begin{array}{c}(0.0182) \\
1.2537 * * *\end{array}$ & $\begin{array}{c}(0.0182) \\
1.2653 * * *\end{array}$ & $\begin{array}{c}(0.0181) \\
1.2546^{* * *}\end{array}$ & $\begin{array}{c}(0.0181) \\
1.2308^{* * *}\end{array}$ & $\begin{array}{c}(0.0181) \\
1.2164^{* * * *}\end{array}$ & $\begin{array}{c}(0.0182) \\
1.2151^{* * *}\end{array}$ & $\begin{array}{c}(0.0182) \\
1.2081^{* * *}\end{array}$ & $\begin{array}{c}(0.0183) \\
1.2136^{* * * *}\end{array}$ \\
\hline & $(0.0246)$ & $(0.0224)$ & $(0.0216)$ & $(0.0213)$ & $(0.0210)$ & $(0.0210)$ & $(0.0208)$ & $(0.0208)$ & $(0.0207)$ & $(0.0207)$ & $(0.0207)$ & $(0.0206)$ & $(0.0206)$ & $(0.0206)$ \\
\hline $\mathrm{N}$ & 1051487 & 1055028 & 1054548 & 1055870 & 1055870 & 1055765 & 1055768 & 1055875 & 1056146 & 1056146 & 1056041 & 1056041 & 1055980 & 1056146 \\
\hline Log lik & -39236 & -47113 & -50681 & -51997 & -52999 & -53156 & -53944 & -54270 & -54546 & -54745 & -54970 & -55024 & -55191 & -55156 \\
\hline Chi2 & $2446 * * *$ & $4763^{* * *}$ & $5684^{* * *}$ & $5808 * * *$ & $5872^{* * *}$ & $5691^{* * *}$ & $5601^{* * *}$ & $5527 * * *$ & $5415^{* * *}$ & $5235^{* * *}$ & $5085^{* * *}$ & $5051^{* * *}$ & $4872^{* * *}$ & $4823 * * *$ \\
\hline
\end{tabular}

Data consist of all WoS articles published in 2001 and are sourced from Thomson Reuters Web of Science Core Collection. Big hits are identified exclusively by home field citations, i.e., citations received from subsequent publications that share at least one common WoS subject category with the focal paper. Being a big hit in home fields using a $t$-year time window means among the top 1\% highly cited papers within the same WoS subject category, based on their home field citations in the $t$-year time window starting from 2001. Field (WoS subject category) fixed effects incorporated.

Robust standard errors in parentheses. ${ }^{* * *} \mathrm{p}<.001,{ }^{* *} \mathrm{p}<.01,{ }^{*} \mathrm{p}<.05,+\mathrm{p}<.10$. 
Table A6. Big hits in foreign fields

\begin{tabular}{|c|c|c|c|c|c|c|c|c|c|c|c|c|c|c|}
\hline & $\begin{array}{c}\text { Top 1\% } \\
\text { cited } \\
(1 \mathrm{y}) \\
\text { logit }\end{array}$ & $\begin{array}{l}\text { Top 1\% } \\
\text { cited } \\
(2 \mathrm{y}) \\
\text { Logit } \\
\end{array}$ & $\begin{array}{l}\text { Top 1\% } \\
\text { cited } \\
\text { (3y) } \\
\text { Logit } \\
\end{array}$ & $\begin{array}{c}\text { Top 1\% } \\
\text { cited } \\
(4 y) \\
\text { logit }\end{array}$ & $\begin{array}{c}\text { Top 1\% } \\
\text { cited } \\
\text { (5y) } \\
\text { logit }\end{array}$ & $\begin{array}{c}\text { Top 1\% } \\
\text { cited } \\
(6 y) \\
\text { logit } \\
\end{array}$ & $\begin{array}{c}\text { Top 1\% } \\
\text { cited } \\
\text { (7y) } \\
\text { logit }\end{array}$ & $\begin{array}{c}\text { Top 1\% } \\
\text { cited } \\
(8 y) \\
\text { logit } \\
\end{array}$ & $\begin{array}{c}\text { Top 1\% } \\
\text { cited } \\
\text { (9y) } \\
\text { logit }\end{array}$ & $\begin{array}{c}\text { Top 1\% } \\
\text { cited } \\
\text { (10y) } \\
\text { logit }\end{array}$ & $\begin{array}{c}\text { Top 1\% } \\
\text { cited } \\
(11 y) \\
\text { logit }\end{array}$ & $\begin{array}{c}\text { Top 1\% } \\
\text { cited } \\
(12 y) \\
\text { logit }\end{array}$ & $\begin{array}{c}\text { Top 1\% } \\
\text { cited } \\
\text { (13y) } \\
\text { logit } \\
\end{array}$ & $\begin{array}{c}\text { Top } 1 \% \\
\text { cited } \\
(14 y) \\
\text { logit }\end{array}$ \\
\hline NOV & $-0.1280^{* *}$ & -0.0072 & 0.0453 & $0.1482^{* * *}$ & $0.1808^{* * *}$ & $0.2162^{* * *}$ & $0.1967 * * *$ & $0.2387 * * *$ & $0.2554 * * *$ & $0.2703^{* * *}$ & $0.2853^{* * *}$ & $0.2779 * * *$ & $0.2766^{* * *}$ & $0.2939 * * *$ \\
\hline CAT2 & $(0.0417)$ & $(0.0335)$ & $(0.0311)$ & $(0.0298)$ & $(0.0289)$ & $(0.0287)$ & $(0.0288)$ & $(0.0285)$ & $(0.0282)$ & $(0.0281)$ & $(0.0280)$ & $(0.0280)$ & $(0.0280)$ & (0.0279) \\
\hline NOV & $-0.2961^{* *}$ & -0.0252 & $0.2839^{* * *}$ & $0.3919 * * *$ & $0.4671^{* * *}$ & $0.4672 * * *$ & $0.5384 * * *$ & $0.5722 * * *$ & $0.6074^{* * *}$ & $0.5884^{* * *}$ & $0.6444^{* * *}$ & $0.6316^{* * *}$ & $0.6269^{* * *}$ & $0.6237 * * *$ \\
\hline САТЗ & $(0.1125)$ & $(0.0820)$ & $(0.0666)$ & $(0.0634)$ & $(0.0599)$ & $(0.0603)$ & $(0.0582)$ & $(0.0576)$ & $(0.0565)$ & $(0.0570)$ & $(0.0559)$ & $(0.0560)$ & $(0.0560)$ & $(0.0563)$ \\
\hline Internation & $0.2633^{* * *}$ & $0.2157 * * *$ & $0.1424^{* * *}$ & $0.0963^{* * *}$ & $0.0634^{* *}$ & $0.0547^{*}$ & $0.0479+$ & 0.0403 & 0.0309 & 0.0336 & 0.0379 & 0.0335 & $0.0467+$ & $0.0600^{*}$ \\
\hline & $(0.0308)$ & $(0.0261)$ & $(0.0247)$ & $(0.0247)$ & $(0.0244)$ & $(0.0245)$ & $(0.0245)$ & $(0.0245)$ & $(0.0245)$ & $(0.0245)$ & $(0.0245)$ & $(0.0245)$ & $(0.0245)$ & $(0.0245)$ \\
\hline Authors & $0.6596 * * *$ & $0.7648 * * *$ & $0.7878 * * *$ & $0.7672 * * *$ & $0.7483 * * *$ & $0.7383 * * *$ & $0.7086 * * *$ & $0.6729 * * *$ & $0.6529 * * *$ & $0.6181^{* * *}$ & $0.5926 * * *$ & $0.5794 * * *$ & $0.5597 * * *$ & $0.5436^{* * *}$ \\
\hline (ln) & $(0.0220)$ & $(0.0196)$ & $(0.0187)$ & $(0.0185)$ & $(0.0182)$ & $(0.0181)$ & $(0.0181)$ & $(0.0181)$ & $(0.0180)$ & $(0.0181)$ & $(0.0181)$ & $(0.0182)$ & $(0.0183)$ & $(0.0184)$ \\
\hline \multirow[t]{2}{*}{ Refs (ln) } & $0.9855^{* * *}$ & $1.1254^{* * *}$ & $1.1885^{* * *}$ & $1.1847 * * *$ & $1.2192^{* * *}$ & $1.1892 * * *$ & $1.1909 * * *$ & $1.1750 * * *$ & $1.1895^{* * *}$ & $1.1811^{* * *}$ & $1.1712^{* * *}$ & $1.1730 * * *$ & $1.1632 * * *$ & $1.1586 * * *$ \\
\hline & $(0.0260)$ & $(0.0231)$ & $(0.0216)$ & $(0.0213)$ & $(0.0212)$ & $(0.0211)$ & $(0.0211)$ & $(0.0211)$ & $(0.0210)$ & $(0.0209)$ & $(0.0207)$ & $(0.0207)$ & $(0.0207)$ & $(0.0208)$ \\
\hline $\mathrm{N}$ & 1044889 & 1054466 & 1055590 & 1055734 & 1055734 & 1056146 & 1056146 & 1055951 & 1056146 & 1056146 & 1056146 & 1055739 & 1056146 & 1056146 \\
\hline Log lik & -34166 & -45431 & -50380 & -51412 & -52954 & -53222 & -53781 & -54143 & -54439 & -54548 & -54819 & -54783 & -55003 & -54878 \\
\hline Chi2 & $4099 * * *$ & $5415^{* * *}$ & $6332 * * *$ & $6468 * * *$ & $6669 * * *$ & $6430^{* * *}$ & $6371^{* * *}$ & $6140 * * *$ & $6185^{* * *}$ & $5945^{* * *}$ & $5887 * * *$ & $5732 * * *$ & $5615^{* * *}$ & $5518 * * *$ \\
\hline
\end{tabular}

Data consist of all WoS articles published in 2001 and are sourced from Thomson Reuters Web of Science Core Collection. Big hits are identified exclusively by foreign field citations, i.e., citations received from subsequent publications that share no common WoS subject categories with the focal paper. Being a big hit in foreign fields using a $t$-year time window means among the top $1 \%$ highly cited papers within the same WoS subject category, based on their foreign field citations in the $t$-year time window starting from 2001. Field (WoS subject category) fixed effects incorporated. Robust standard errors in parentheses. ${ }^{* * *} \mathrm{p}<.001,{ }^{* *} \mathrm{p}<.01,{ }^{*} \mathrm{p}<.05,+\mathrm{p}<.10$. 
Table A7. Big hits: novelty interact with JIF

\begin{tabular}{|c|c|c|c|c|c|c|c|c|c|c|c|c|c|c|}
\hline & $\begin{array}{l}\text { Top 1\% } \\
\text { cited } \\
(1 \mathrm{y}) \\
\text { logit }\end{array}$ & $\begin{array}{l}\text { Top 1\% } \\
\text { cited } \\
(2 y) \\
\text { Logit }\end{array}$ & $\begin{array}{l}\text { Top 1\% } \\
\text { cited } \\
\text { (3y) } \\
\text { logit }\end{array}$ & $\begin{array}{c}\text { Top 1\% } \\
\text { cited } \\
(4 y) \\
\text { logit }\end{array}$ & $\begin{array}{l}\text { Top 1\% } \\
\text { cited } \\
(5 y) \\
\text { logit }\end{array}$ & $\begin{array}{l}\text { Top 1\% } \\
\text { cited } \\
\text { (6y) } \\
\text { Logit }\end{array}$ & $\begin{array}{l}\text { Top 1\% } \\
\text { cited } \\
(7 y) \\
\text { logit }\end{array}$ & $\begin{array}{l}\text { Top 1\% } \\
\text { cited } \\
(8 y) \\
\text { logit }\end{array}$ & $\begin{array}{l}\text { Top 1\% } \\
\text { cited } \\
(9 y) \\
\text { logit }\end{array}$ & $\begin{array}{l}\text { Top 1\% } \\
\text { cited } \\
(10 y) \\
\text { logit }\end{array}$ & $\begin{array}{l}\text { Top 1\% } \\
\text { cited } \\
\text { (11y) } \\
\text { logit }\end{array}$ & $\begin{array}{l}\text { Top 1\% } \\
\text { cited } \\
(12 y) \\
\text { Logit }\end{array}$ & $\begin{array}{l}\text { Top 1\% } \\
\text { cited } \\
\text { (13y) } \\
\text { logit }\end{array}$ & $\begin{array}{l}\text { Top 1\% } \\
\text { cited } \\
(14 y) \\
\text { logit }\end{array}$ \\
\hline NOV & $-0.1436 * *$ & 0.0021 & 0.0765 & $0.1255^{* *}$ & $0.2129^{* * *}$ & $0.2310^{* * *}$ & $0.2382^{* * *}$ & $0.2540^{* * *}$ & $0.2993^{* * *}$ & $0.3354^{* * *}$ & $0.3315^{* * *}$ & $0.3068^{* * *}$ & $0.3502^{* * *}$ & $0.3417^{* * *}$ \\
\hline $\begin{array}{l}\text { NOV } \\
\text { CAT3 }\end{array}$ & $\begin{array}{c}-0.1364 \\
(0.1438)\end{array}$ & $\begin{array}{c}0.1931+ \\
(0.1138)\end{array}$ & $\begin{array}{c}0.4661^{* * *} \\
(0.0989)\end{array}$ & $\begin{array}{c}0.6375^{* * * *} \\
(0.0899)\end{array}$ & $\begin{array}{c}0.6671^{* * *} \\
(0.0877)\end{array}$ & $\begin{array}{c}0.6769 * * * \\
(0.0859)\end{array}$ & $\begin{array}{c}0.7210^{* * * *} \\
(0.0837)\end{array}$ & $\begin{array}{c}0.7068^{* * * *} \\
(0.0836)\end{array}$ & $\begin{array}{c}0.7489 * * * * \\
(0.0814)\end{array}$ & $\begin{array}{c}0.7463 * * * \\
(0.0814)\end{array}$ & $\begin{array}{c}0.7449 * * * \\
(0.0807)\end{array}$ & $\begin{array}{c}0.7654^{* * * *} \\
(0.0793)\end{array}$ & $\begin{array}{c}0.7781^{* * * *} \\
(0.0787)\end{array}$ & $\begin{array}{c}0.7867 * * * * \\
(0.0779)\end{array}$ \\
\hline JIF & $1.5661^{* * * *}$ & $1.9481^{* * *}$ & $2.0416^{* * *}$ & $2.0346^{* * *}$ & $2.0388^{* * *}$ & $1.9851^{* * *}$ & $1.9432^{* * *}$ & $1.9035^{* * *}$ & $1.8743^{* * *}$ & $1.8537^{* * *}$ & $1.8140^{* * *}$ & $1.7846^{* * *}$ & $1.7683^{* * *}$ & $1.7338^{* * *}$ \\
\hline TOP10\% & $(0.0274)$ & $(0.0252)$ & $(0.0249)$ & $(0.0247)$ & $(0.0245)$ & $(0.0243)$ & $(0.0242)$ & $(0.0241)$ & $(0.0240)$ & $(0.0240)$ & (0.0239) & $(0.0238)$ & $(0.0239)$ & $(0.0238)$ \\
\hline JIF & $-0.1441+$ & $-0.2263^{* * *}$ & $-0.2189 * * *$ & $-0.2386 * * *$ & $-0.3294 * * *$ & $-0.3228 * * *$ & $-0.3052^{* * * *}$ & $-0.2834^{* * *}$ & $-0.3278 * * *$ & $-0.3437 * * *$ & $-0.3232 * * *$ & $-0.3016^{* * *}$ & $-0.3411 * * *$ & $-0.3414^{* * *}$ \\
\hline $\begin{array}{l}\text { NOP10\% } \\
\text { NOV } \\
\text { CAT2 }\end{array}$ & $(0.0 / 80)$ & (0.0658) & $(0.0626)$ & (0.0609) & (0.0592) & (0.0584) & & $(0.05 / 3)$ & & & & & & $(0.0560)$ \\
\hline $\begin{array}{l}\text { JIF } \\
\text { TOP10\%* } \\
\text { NOV } \\
\text { CAT3 }\end{array}$ & $\begin{array}{c}-0.2052 \\
(0.2072)\end{array}$ & $\begin{array}{c}-0.5628 * * \\
(0.1631)\end{array}$ & $\begin{array}{c}-0.6241^{* * *} \\
(0.1409)\end{array}$ & $\begin{array}{c}-0.6226 * * * \\
(0.1288)\end{array}$ & $\begin{array}{c}-0.6392 * * * \\
(0.1262)\end{array}$ & $\begin{array}{c}-0.5684 * * * \\
(0.1233)\end{array}$ & $\begin{array}{c}-0.5894 * * * \\
(0.1219)\end{array}$ & $\begin{array}{c}-0.5909 * * * \\
(0.1228)\end{array}$ & $\begin{array}{c}-0.5779 * * * \\
(0.1203)\end{array}$ & $\begin{array}{c}-0.5627^{* * *} \\
(0.1204)\end{array}$ & $\begin{array}{c}-0.5374 * * * \\
(0.1197)\end{array}$ & $\begin{array}{c}-0.5791 * * * \\
(0.1196)\end{array}$ & $\begin{array}{c}-0.5816^{* * * *} \\
(0.1193)\end{array}$ & $\begin{array}{c}-0.5169 * * * \\
(0.1172)\end{array}$ \\
\hline $\begin{array}{l}\text { Internation } \\
\text { al }\end{array}$ & $\begin{array}{c}0.1901^{* * *} \\
(0.0280)\end{array}$ & $\begin{array}{c}0.1488^{* * *} \\
(0.0246)\end{array}$ & $\begin{array}{c}0.0907 * * * \\
(0.0241)\end{array}$ & $\begin{array}{c}0.0707 * * \\
(0.0240)\end{array}$ & $\begin{array}{c}0.0535^{*} \\
(0.0238)\end{array}$ & $\begin{array}{l}0.0586 * \\
(0.0238)\end{array}$ & $\begin{array}{l}0.0554^{*} \\
(0.0239)\end{array}$ & $\begin{array}{l}0.0489 * \\
(0.0239)\end{array}$ & $\begin{array}{c}0.0515^{*} \\
(0.0239)\end{array}$ & $\begin{array}{l}0.0543^{*} \\
(0.0239)\end{array}$ & $\begin{array}{l}0.0484^{*} \\
(0.0240)\end{array}$ & $\begin{array}{c}0.0289 \\
(0.0241)\end{array}$ & $\begin{array}{c}0.0216 \\
(0.0241)\end{array}$ & $\begin{array}{c}0.0312 \\
(0.0241)\end{array}$ \\
\hline $\begin{array}{l}\text { Authors } \\
\text { (ln) }\end{array}$ & $\begin{array}{c}0.4802^{* * *} \\
(0.0216)\end{array}$ & $\begin{array}{c}0.6222^{* * *} \\
(0.0199)\end{array}$ & $\begin{array}{c}0.6751^{* * *} \\
(0.0195)\end{array}$ & $\begin{array}{c}0.6507^{* * *} \\
(0.0193)\end{array}$ & $\begin{array}{c}0.6193^{* * *} \\
(0.0190)\end{array}$ & $\begin{array}{c}0.6033^{* * *} \\
(0.0189)\end{array}$ & $\begin{array}{c}0.5813^{* * * *} \\
(0.0188)\end{array}$ & $\begin{array}{c}0.5501 * * * \\
(0.0188)\end{array}$ & $\begin{array}{c}0.5190^{* * *} \\
(0.0188)\end{array}$ & $\begin{array}{c}0.4942^{* * *} \\
(0.0188)\end{array}$ & $\begin{array}{c}0.4737^{* * *} \\
(0.0189)\end{array}$ & $\begin{array}{c}0.4481^{* * *} \\
(0.0189)\end{array}$ & $\begin{array}{c}0.4366^{* * *} \\
(0.0189)\end{array}$ & $\begin{array}{c}0.4167 * * * \\
(0.0190)\end{array}$ \\
\hline Log lik & -39508 & -46753 & -48568 & -49580 & -50638 & -51165 & -51537 & -51998 & -52395 & -52481 & -52831 & -53062 & -53209 & -53472 \\
\hline Chi2 & $8514 * * *$ & $14380 * * *$ & $16198 * * *$ & $16406 * * *$ & $16649 * * *$ & $16089 * * *$ & $15574 * * *$ & $15093 * * *$ & $14746 * * *$ & $14305^{* * *}$ & $13933^{* * *}$ & $13624 * * *$ & $13310^{* * *}$ & $12999 * * *$ \\
\hline
\end{tabular}

Data consist of all WoS articles published in 2001 and are sourced from Thomson Reuters Web of Science Core Collection. Big hits are identified based on all citations (i.e., both home and foreign field citations). Being a big hit in a $t$-year time window means among the top $1 \%$ highly cited papers within the same WoS subject category and publication year, based on their citations in the $t$-year time window starting from 2001 . Field (WoS subject category) fixed effects incorporated. Robust standard errors in parentheses. ${ }^{* * *} \mathrm{p}<.001,{ }^{* *} \mathrm{p}<.01,{ }^{*} \mathrm{p}<.05,+\mathrm{p}<.10$. 


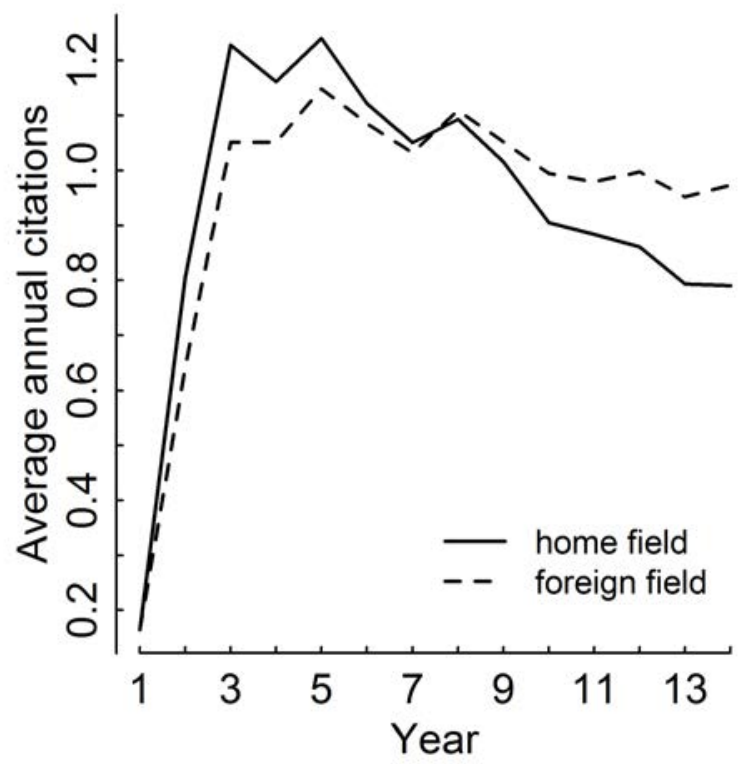

Figure A1. Average annual citations. The average number of annual citations over time, separating home and foreign fields. Data consist of 1,056,936 WoS articles published in 2001 and are sourced from Thomson Reuters Web of Science Core Collection. 


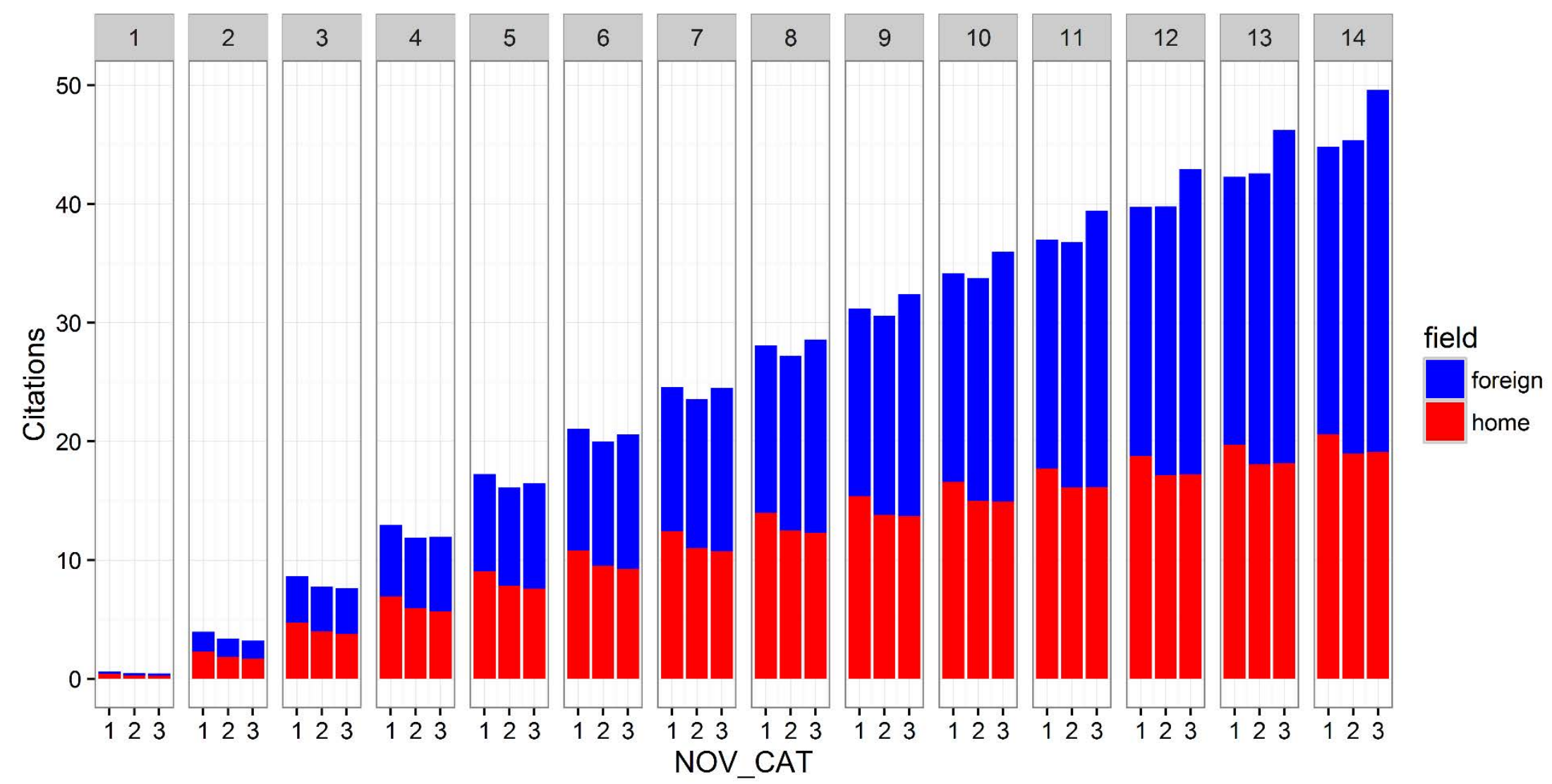

Figure A2. Estimated cumulative number of citations by novelty classes and time windows, separating home and foreign field citations. Estimates are based on a set of Poisson regressions. Using negative binomial models yields similar results. Data consist of 1,056,936 WoS articles published in 2001 and are sourced from Thomson Reuters Web of Science Core Collection. 


\section{Appendix III: Robustness analysis}

In summary, we find that novel papers have (1) a higher dispersion in citations, (2) a higher chance of being a big hit in the long term, (3) a higher chance of being cited by big hits, (4) a broader impact across scientific fields, (5) a larger share of citations from foreign fields, (6) not a higher chance of being highly cited in home field, (7) a higher chance of being highly cited in foreign field, (8) a lower chance of being a big hit in the short term, and (9) are published in journals with lower Impact Factors. In this section we test the robustness of these nine findings.

\section{III.1. Scientific field heterogeneity}

Although we control for scientific field effects, and some of our measures for novelty (i.e., highly novel) and impact (e.g., big hits) are field specific, it is nevertheless possible that the relationship between novelty and impact is field specific. To test this possibility, we examine whether our main findings are robust across scientific fields, replicating the whole set of analyses separately by field. We use four groups: AH (Arts and Humanities), LS (Life Sciences), PSE (Physical Sciences and Engineering), and SS (Social Sciences). We also distinguish between LS2 (Medicine) and the rest (LS1) within LS and distinguish between PSE2 (Computer Sciences; Engineering) and the rest (PSE1) within PSE. Both LS2 and PSE2 are the more applied counterparts of LS1 and PSE1. In total, we run separate regressions for the following eight groups: AH, LS, LS1, LS2, PSE, PSE1, PSE2, and SS. While our findings are robust for LS and PSE fields, they are less robust for AH and SS fields. Specifically, findings, (1) higher dispersion, (8) fewer short-term big hits, and (9) lower JIF for novel papers, are not robust for $\mathrm{AH}$, and finding (1) higher dispersion is not robust for SS. This may suggest that the relationship between novelty and impact varies across fields and our findings hold most specifically for hard sciences and engineering. However, it may also be an artifact of data limitations. The WoS coverage for humanities and social sciences is much smaller than hard sciences, so we have much fewer observations for AH and SS than for the hard sciences. More importantly, because of this coverage issue, using the WoS data does not capture sufficiently all the publishing and referencing transactions in humanities and social sciences (Hicks, 2004), which is required for constructing measures of novelty and impact. 


\section{III.2. Novelty measure variations}

First, we test whether our findings hold when we use alternative formulas for our novelty measure. As explained in section 3.1, our novelty measure is essentially the number of new referenced journal pairs, weighted by the distance between the newly paired journals (i.e., weighted sum). Alternatively we can use the novelty score of the most distinct pair among all the new pairs (i.e., max score) or the proportion of all journal pairs that are new, weighted by the distance (i.e., weighted share).

The maximum novelty score,

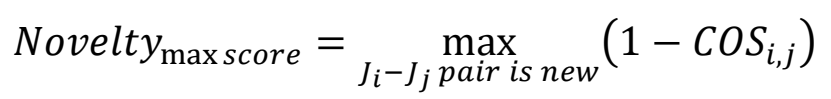

focuses exclusively on the novelty score of the most distant new journal pair instead of mixing both the number and the difficulty of new journal pairs. We find using the max score approach that all our findings hold, except finding 6, specifically, while max score CAT2 also has a significantly negative effect on being highly cited in the home field, max score CAT3 has a small but significantly $(p=0.09)$ positive effect. One possible explanation is that papers with a small number of very distant new combinations but at same time a large number of conventional combinations within the home field are likely to score high on the max score measure, and the large number of home field combinations makes the paper more likely to be accepted by the home field. For a further assessment we compare the size of the effect. Highly novel defined by max score, compared with defined by weighted sum, has a larger effect on the likelihood of being a long-term big hit (i.e., finding 2) but smaller effects for all other findings, i.e., all nine findings except 2 and 6. We conclude that our weighted sum approach captures at least more of the "high risk", if not also the "high gain,” nature of novel research.

Because of the concern that our weighted sum measure of novelty might be over-dependent on the number of references in the focal paper, which including the number of references in the regression analysis may not sufficiently control for, we also inspect the weighted share approach, which essentially normalizes our novelty measure for the number of journal pairs. It can also be 
viewed as a reversed and weighted network density ${ }^{9}$ measure with the number of missing ties (i.e., new ties which did not exist in previous years, weighted by the distance) in the numerator and the size of the network (i.e., the number of all journal pairs regardless new or not) in the denominator. Specifically,

$$
\text { Novelty }_{\text {weighted share }}=\frac{1}{n} \sum_{J_{i}-J_{j} \text { pair is new }}\left(1-\operatorname{COS}_{i, j}\right)
$$

where $n$ is the number of all co-cited journal pairs. All findings hold using this weighted share approach. In terms of the size of the effect, highly novel defined by weighted share, compared with defined by weighted sum, has larger effects on finding 8 (i.e., fewer short-term big hits) and on finding 9 (i.e., lower JIF) but smaller effects for all other findings. The weighted share measure imposes a penalty on papers with a large number of referenced journals, in other words, papers with a larger network of referenced journals. We believe that network size is also an important aspect of combinatorial novelty and therefore should not be eliminated from the analysis. Specifically, a larger network making the same number of new connections should not be evaluated as less novel than a smaller network. Furthermore, the weighted share measure is very sensitive when a paper has very limited number of referenced journals. Therefore, we prefer our weight sum measure to the weighted share approach.

Second, our novelty indicator used in the analysis excluded the 50\% least cited journals and required reuse of the new combination in the next three years. To check the sensitivity of the analysis to these choices, we replicate the analysis without these restrictions. In addition, although most new journals are already excluded in the analysis because they are typically among the lower cited journals, we also checked the results excluding new journals from the calculation of novelty. Moreover, Boyack and Klavans (2014) warned that the atypicality measure in Uzzi et al. (2013) is confounded with citing star journals, such as Science and Nature. Our novelty measure is unlikely to be confounded with citing star journals, which are so highly cited that combining them with any other journals is very unlikely to be new. Nevertheless, we check results excluding the top $10 \%$ highly cited journals, as well as

\footnotetext{
${ }^{9}$ Network density is the proportion of all possible ties that are actually present in the network.
} 
multidisciplinary journals. In summary, we test robustness of our findings using the following variations of the novelty measure: (a) no restrictions, (b) only exclude the $50 \%$ least cited journals, (c) only require reuse in 3 years, (d) only exclude new journals, (e) exclude the 50\% least cited journals, require reuse in 3 years, and exclude the 10\% top cited journals, and (f) exclude the 50\% least cited journals, require reuse in 3 years, and exclude the $10 \%$ top cited and multidisciplinary journals. Our findings are robust using all these alternative specifications.

Third, to accommodate the skewness of the indicator, we created three novelty categories. When we duplicate the results using the natural logarithm transformed continuous novelty score in the regression, all results are robust.

Fourth, we classified highly novel papers as the top 1\% novel papers in the same subject category. We also use different thresholds for the categorization, specifically, classifying the top $5 \%$ or $0.1 \%$ papers as highly novel. All results are robust, and the changes in effect size are consistent with what we would expect from comparing the coefficients on highly and moderately novel classes in our reported results. For example, compared with our reported results for classifying the top 1\% papers as highly novel, highly novel would have a larger effect on the likelihood of big hits when classifying top $0.1 \%$ papers as highly novel but a smaller effect when classifying top 5\% papers as highly novel.

\section{III.3. Novelty versus atypicality}

We compare our novelty indicator with the Uzzi et al. (2013) measure of atypicality. For a scientific publication, Uzzi et al. (2013) calculated the commonness score for all its referenced journal pairs, where the commonness score is a z-score, (i.e. the number of observed co-citations between the pair - the number of expected co-citations) / standard deviation of the co-citations) and labelled the lowest $10^{\text {th }}$ percentile of this series of commonness scores as their indicator of novelty. To distinguish it from our measure of novelty, we label their indicator as atypicality. Lee et al. (2015) used an adapted version in their study. Specifically, they used the ratio between the number of observed co-citations and the number of expected co-citations as the commonness score of a journal pair, instead of the z-score. In addition, they take the natural logarithm of the commonness score and add a negative sign, obtaining a roughly normally distributed variable positively associated with atypicality, while the commonness score is negatively associated with 
atypicality. Here we follow this adapted version to calculate the Uzzi et al. (2013) indicator for our sampled papers. To make the comparison, we categorize the continuous atypicality indicator into three classes with the same proportion of papers in each of the three classes, specifically, ATP CAT $=3$ if top $1 \%$ in the same WoS subject category and publication year, 2 if below top $1 \%$ but above top $10 \%$, and 1 for all others. In addition, we also compare the continuous versions of both atypicality and our novelty scores. Specifically, we assess results of six sets of regressions using the following independent variables: (a) novelty categories (NOV CAT), i.e., main results reported in the text, (b) atypicality categories (ATP CAT), (c) NOV CAT and ATP CAT together, (d) novelty score, (e) atypicality score, (f) novelty and atypicality scores together.

We focus on two criteria for assessing the results: the size of the effect and the consistency of the results across these six settings. When both categorical novelty and atypicality are in the regression, i.e., in setting (c), all effects of novelty (i.e., NOV CAT2 and NOV CAT3 on findings 1-9) remain consistent. Atypicality classes, compared with novelty classes, have smaller and insignificant effects on (1) higher dispersion and (8) fewer short-term big hits; smaller but significant effect on (3) higher indirect impact; larger effect on (2) more long-term big hits and (4) broader impact, (5) higher share of foreign field citations, (6) fewer big hits in home field, and (7) more big hits in foreign field; and reversed effect on (9) low JIF ${ }^{10}$. When having both continuous novelty and atypicality scores in the regressions, i.e., in setting (f), again all the effects of novelty remain consistent, while the atypicality score, compared with the novelty score, has reversed but insignificant effect on (1) higher dispersion; reversed and significant effect on (8) fewer short-term big hits and (9) lower JIF; smaller and insignificant effect on (6) fewer big hits in home field; smaller and significant effect on (3) higher indirect impact; and larger effect on (2) more long-term big hits, (4) broader impact, (5) higher share of foreign field citations, and (7) more big hits in foreign field. Based on the comparison of effect size, it seems that our novelty indicator better captures the "high risk" nature of novel research than does the atypicality score. In terms of "high gain," atypicalty better captures the higher direct impact and broader impact, while novelty better captures the indirect impact of stimulating follow-on breakthroughs.

\footnotetext{
${ }^{10}$ Specifically, ATP CAT2 has a positive and significant effect, while ATP CAT3 has a positive but insignificant effect on JIF.
} 
In terms of consistency across these six settings, our novelty measure has considerably more reliable and robust behavior than atypicality. While effects of our novelty measure are robust across all six setting, the results of atypicality are not consistent across settings. For example, ATP CAT3 has a significantly negative effect on short-term big hits, but atypicality score has a significantly positive effect; atypicality has a significantly negative effect on JIF in setting (b) but a positive effect in other settings; and atypicality has a significantly negative effect on big hits in home field when treated alone in setting (e) but an insignificantly negative effect when treated together with novelty in setting (f). Overall, we conclude that our novelty indicator behaves more reliably, captures more the "high risk" nature of novel research, and measures aspects of research not captured by the atypicality measure. 